\title{
Emerging SARS-CoV-2 Variants: Genetic Variability and Clinical Implications
}

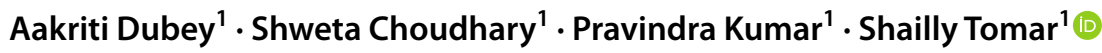 \\ Received: 9 July 2021 / Accepted: 8 November 2021 / Published online: 14 December 2021 \\ (c) The Author(s), under exclusive licence to Springer Science+Business Media, LLC, part of Springer Nature 2021
}

\begin{abstract}
The sudden rise in COVID-19 cases in 2020 and the incessant emergence of fast-spreading variants have created an alarming situation worldwide. Besides the continuous advancements in the design and development of vaccines to combat this deadly pandemic, new variants are frequently reported, possessing mutations that rapidly outcompeted an existing population of circulating variants. As concerns grow about the effects of mutations on the efficacy of vaccines, increased transmissibility, immune escape, and diagnostic failures are few other apprehensions liable for more deadly waves of COVID-19. Although the phenomenon of antigenic drift in new variants of SARS-CoV-2 is still not validated, it is conceived that the virus is acquiring new mutations as a fitness advantage for rapid transmission or to overcome immunological resistance of the host cell. Considerable evolution of SARS-CoV-2 has been observed since its first appearance in 2019, and despite the progress in sequencing efforts to characterize the mutations, their impacts in many variants have not been analyzed. The present article provides a substantial review of literature explaining the emerging variants of SARS-CoV-2 circulating globally, key mutations in viral genome, and the possible impacts of these new mutations on prevention and therapeutic strategies currently administered to combat this pandemic. Rising infections, mortalities, and hospitalizations can possibly be tackled through mass vaccination, social distancing, better management of available healthcare infrastructure, and by prioritizing genome sequencing for better serosurveillance studies and community tracking.
\end{abstract}

\section{Introduction}

Erratic surge and increased frequency of new COVID-19 cases in 2020 have created a situation of havoc worldwide, accounting for an unprecedented impact on modern human civilization, resulting in global infections of more than 200 million and 4.5 million deaths till now [1]. SARS-CoV-2, the causative agent of the current ongoing pandemic of COVID-19, is a rapidly evolving RNA virus that is continuously accruing genomic mutations as it is spreading globally. Coronaviruses have evolved with a genetic proofreading process to sustain their long genomic RNA and to keep their sequence diversity low [2]. Although the rate of viral

Aakriti Dubey and Shweta Choudhary have contributed equally to the manuscript.

Shailly Tomar

shailly.tomar@bt.iitr.ac.in

1 Department of Biosciences and Bioengineering, Indian Institute of Technology Roorkee, Roorkee, Uttarakhand 247667, India evolution is decelerated by the RNA proofreading capability of its replication machinery, the virus is progressively evolving, giving rise to more potent variants that are outcompeting the original strain and becoming globally dominant [3]. The virus is constantly evolving with either the substitution or deletion mutations (mostly in the Spike (S) protein), majority of which are expected to be neutral towards virus pathogenicity or transmissibility (Figs. 2, 3b, c, and 4). However, a small minority of these mutations impacts virus phenotype, altering virus biology such as differential virulence, antigenicity or transmissibility [4-7].

The pattern of viral spread, increased transmissibility, infectivity, and immunological resistance consolidated with the frequent substitutions or deletions in the S protein of SARS-CoV-2 suggests that the mutations are imparting a fitness advantage for better transmission to this virus. These mutations are possibly associated with epidemiological processes such as bottleneck effect, founder effect, or antigenic drift [8]. Given the rapidity with which the virus is emerging, it is important to characterize the neutralization efficacy of currently deployed vaccines as well as the sensitivity of diagnostic tests against the circulating variants to ameliorate 
further spread of SARS-CoV-2 infections. Failure to detect the $\mathrm{S}$ protein or the gene encoding $\mathrm{S}$ protein in antigen capture assays or RT-PCR has been reported in the case of certain variants. Such misdiagnosis may underestimate the actual number of cases and will pose a risk of further viral spread with false-negative results [9].

Variants will continue to emerge rendering the future of the COVID-19 pandemic unpredictable, so to preclude more fatalities, effective interventions are required for quick characterization of new mutations in the viral genome to avoid misdiagnosis or to control further spread. The present review article describes newly identified variants of SARS-CoV-2, providing additional insights into notable genomic mutations, effects of these mutations on disease progression, and changes in their susceptibility to vaccines and therapeutics.

\section{The SARS-CoV-2 Genome}

SARS-CoV-2 is a single-stranded positive-sense RNA (+ssRNA) virus with a genome of $\sim 30 \mathrm{~kb}$ in length, comprising 14 open-reading frames (ORFs) that encode the numerous viral proteins [10]. Towards the $5^{\prime}$ end of the viral genome lies two overlapping ORFs (ORF1a and
ORF1b) that are translated to produce polypeptides pp1a and $\mathrm{pp} 1 \mathrm{ab}$. These polypeptides are cleaved further to produce 16 non-structural proteins (nsPs) [11]. The $3^{\prime}$ end of the viral genome encompasses 13 ORFs encoding four structural proteins [Envelope (E), Nucleocapsid (N), Membrane $(\mathrm{M})$, and Spike (S)], and nine accessory factors (ORF3a, 3b, 6, 7a, 7b, 8, 9a, 9b, and 10) (Fig. 1a) [10]. Structurally, SARS-CoV-2 is an enveloped virus composed of trimers of surface anchored S protein (Fig. 2a) [12]. Entry of SARS$\mathrm{CoV}-2$ is mediated by sequential cleavage of $\mathrm{S}$ protein by furin at the S1/S2 site and by transmembrane serine protease 2 (TMPRSS2) at the $\mathrm{S} 2$ ' site for facilitating fusion of membranes (Fig. 1c). In contrast to SARS-CoV containing TMPRSS2, the introduction of the RRAR poly-basic furin cleavage site in SARS-CoV-2 at the S1/S2 site is considered a key determinant of viral spread, infectivity, and transmissibility (Fig. 1c) [13].

The $\mathrm{S} 1$ subunit (Fig. 3a) consists of an $\mathrm{N}$-terminal domain (NTD) and a receptor-binding domain (RBD) (Fig. 3a), responsible for recognizing and interacting with the angiotensin converting enzyme 2 (ACE2) receptor of the host cell and serves as a critical epitope for neutralizing antibodies (Figs. 1c and 2a) [14]. In addition, the S2 subunit of the S protein (Fig. 3a) assists in the fusion

a

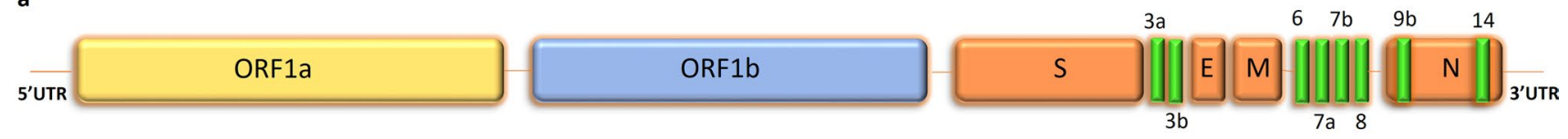

b

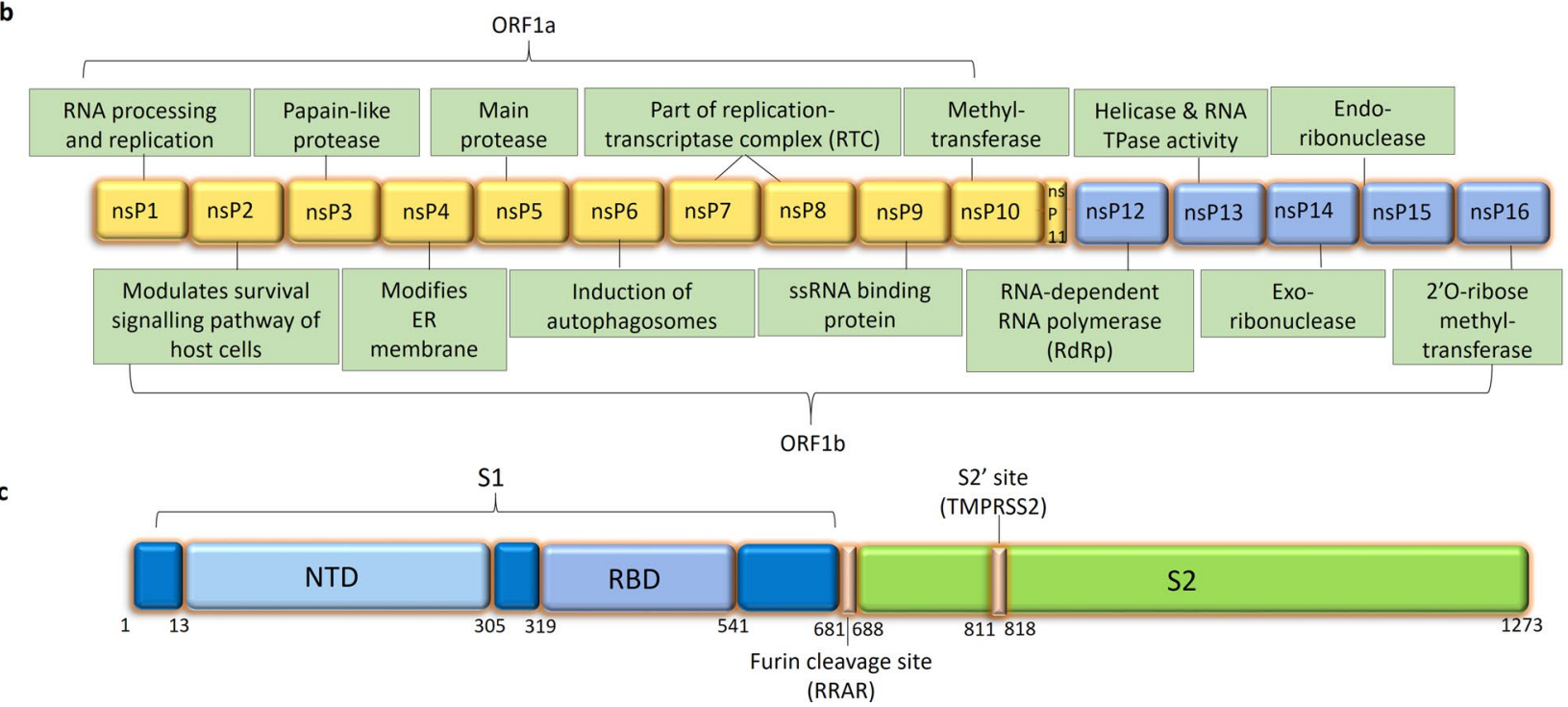

Fig. 1 Viral genome and functional domains in SARS-CoV-2. a Schematic annotation of SARS-CoV-2 genomic composition. Genome of SARS-CoV-2 is $30 \mathrm{~kb}$ in length comprising 14 ORFs, responsible for producing structural and non-structural proteins (nsPs). b N-terminus region, spanning more than two-third portion of the viral genome, is translated to produce polyprotein of nsPs, which is proteolytically cleaved by main protease (nsP5) and papain-like protease (nsP3) to form the replicase-transcriptase complex for viral replication. c Schematic representation of domains of SARS-CoV-2 S protein. S1 subunit comprises N-terminal domain (NTD) and receptor-binding domain (RBD). Canonical location of S1/S2 (Furin site) and S2' (TMPRSS2) cleavage sites are indicated in S protein 
Fig. 2 a Cartoon representation of SARS-CoV-2 homotrimeric $\mathrm{S}$ protein interacting with human angiotensin converting enzyme2 (ACE2) via its receptor-binding domain (RBD). The three-dimensional complex structure of RBD and ACE2 was retrieved from the RCSBProtein data bank (PDB ID: 7DF4). ACE2 has been shown in cyan while magenta, yellow and green cartoons represent the three $\mathrm{S}$ proteins linked together to form a homotrimer. b Key interactions of the receptorbinding domain (RBD) of $\mathrm{S}$ protein to human ACE2 (PDB ID: 6M0J) displayed using cartoon representation. Important RBD mutations circulating in emerging variants, c E484K, d E484Q, e K417T, f K417N, g N501Y, h Y453F, i N439K, j N440K, k L452R, and I S477N are represented in green sticks models. RBD is colored in magenta, ACE2 is colored in cyan, and the key residues at the RBD-ACE2 interface are shown as stick models (Color figure online)

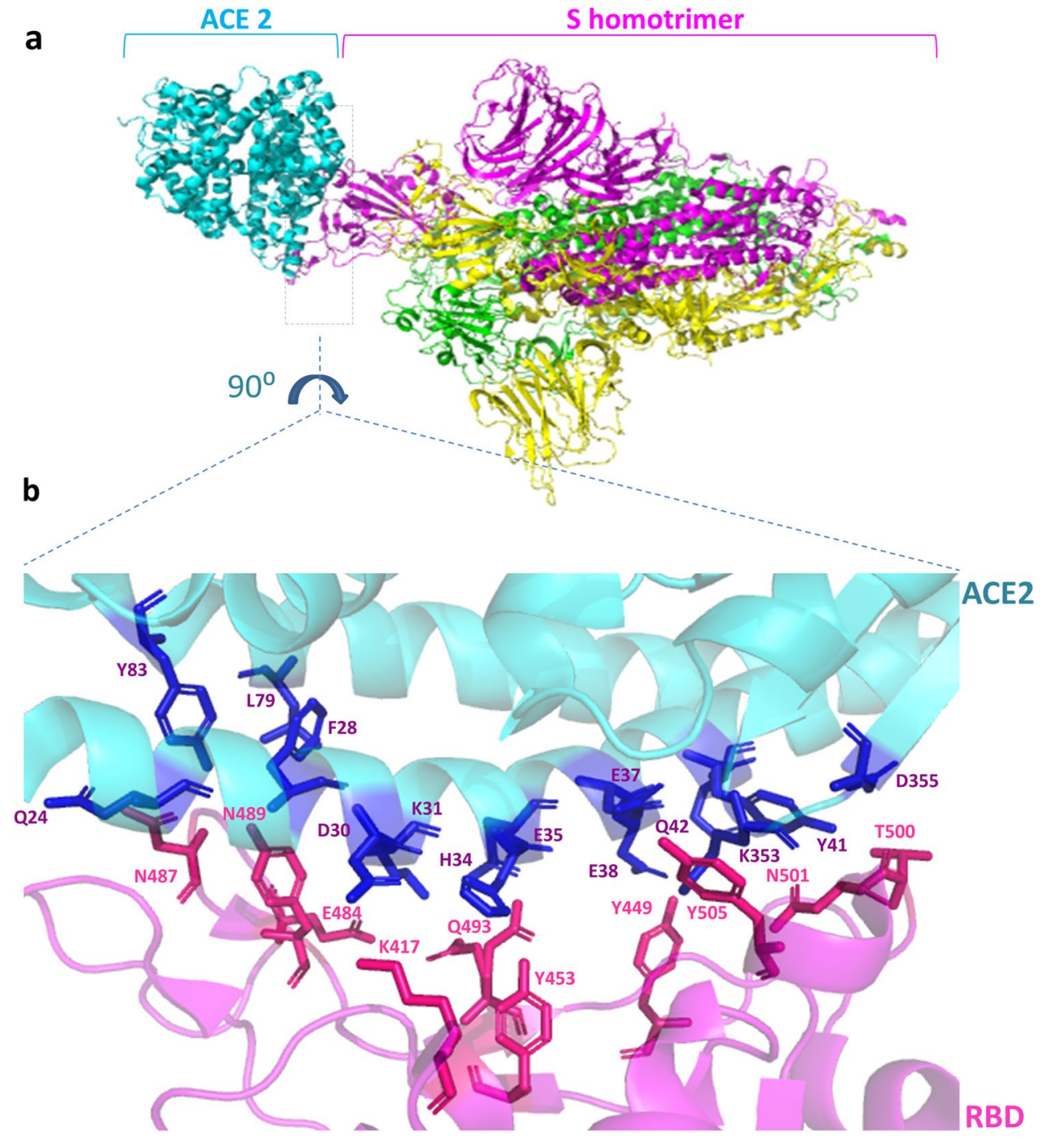

of viral and host cell membranes [14]. Upon virus entry, translation of ORF1a leads to the production of $10 \mathrm{nsPs}$ and a polypeptide (pplab) of $16 \mathrm{nsPs}$ is produced from ORF1b (Fig. 1b) [10]. pp $1 \mathrm{ab}$ is proteolytically cleaved by viral proteases, papain-like protease (nsP3), and the main protease (nsP5) to form the replicase-transcriptase complex (RTC), essential for replication of the virus [10]. The RTC is composed of the primase complex formed by nsP7-nsP8, RNA-dependent RNA polymerase (nsP12, $\mathrm{RdRp}$ ), exoribonuclease (nsP14), endonuclease (nsP15), and methyltransferases (nsP10 and nsP16) (Fig. 1b) [10]. The $\mathrm{N}$ protein binds to the viral RNA and forms a ribonucleoprotein core. It plays a pivotal role in virus replication and genome packaging [15]. The $\mathrm{M}$ protein is responsible for the assembly of viral particles. It also inhibits NF- $\kappa B$ and downregulates the host antiviral response (Fig. 1a) [15]. The viral E protein is a multi-functional protein and is implicated in viral pathogenesis, assembly, budding, and envelope formation of new virions (Fig. 1a) [15]. Accessory genes are distributed between the structural genes, and their functions are still unknown [15].

\section{Nomenclature for SARS-CoV-2 Variants}

Newly emerging variants of SARS-CoV-2 have been categorized into different categories by the SARS-CoV-2 Interagency Group (SIG) of the US Department of Health and Human Services (HHS) for better coordination among various US departments and agencies to actively monitor and characterize the emerging variants and to screen critical countermeasures against them. These categories are based on the vulnerability of the variants to prevailing treatments and vaccines. Variants associated with increased transmissibility or reduced viral neutralization by antibodies or other treatments are classified under variants of interest (VOI). In 
Fig. 2 (continued)

C

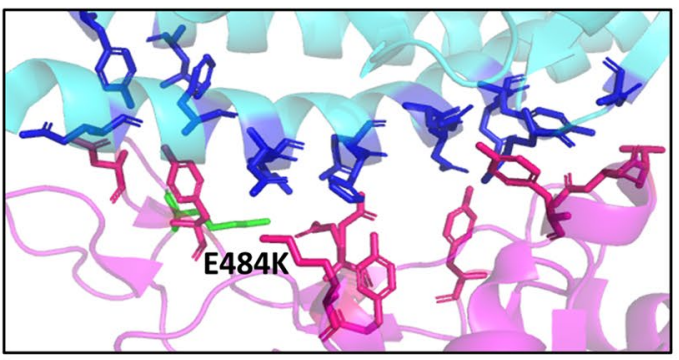

e

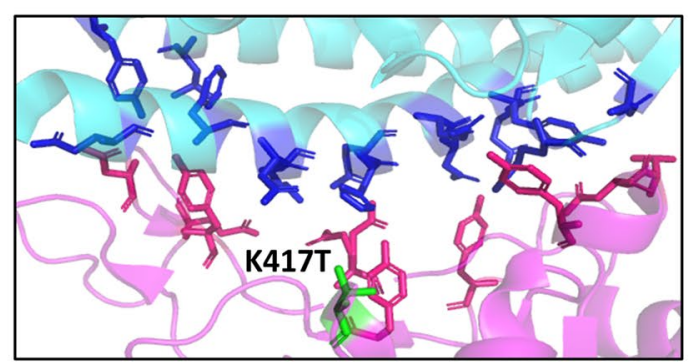

g

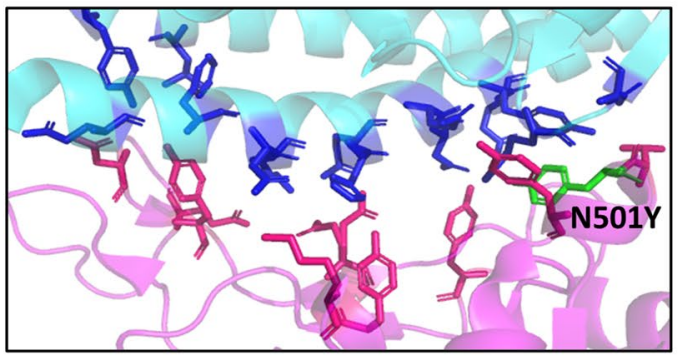

i

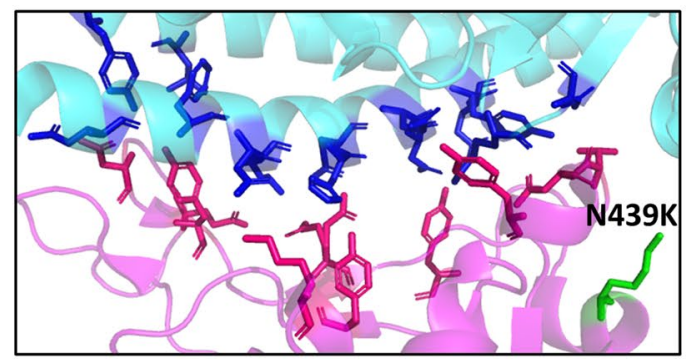

k

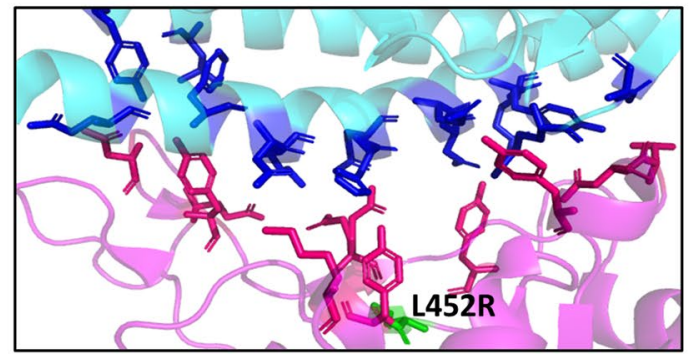

d

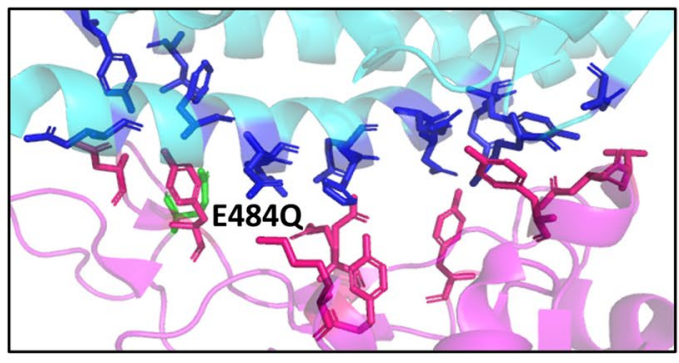

f

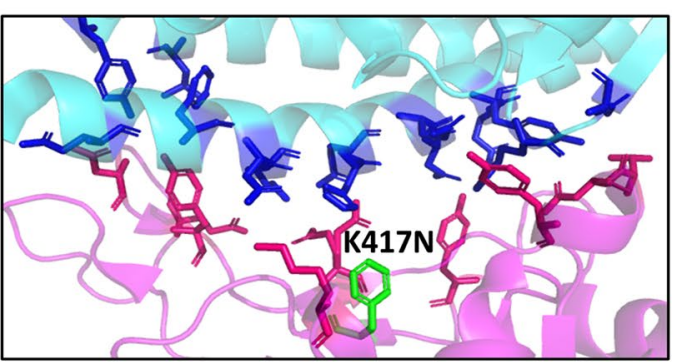

h

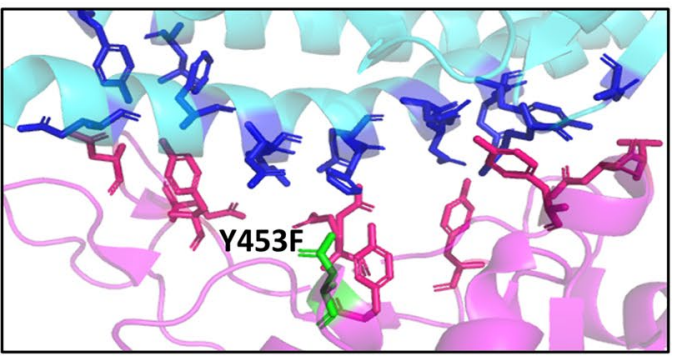

j

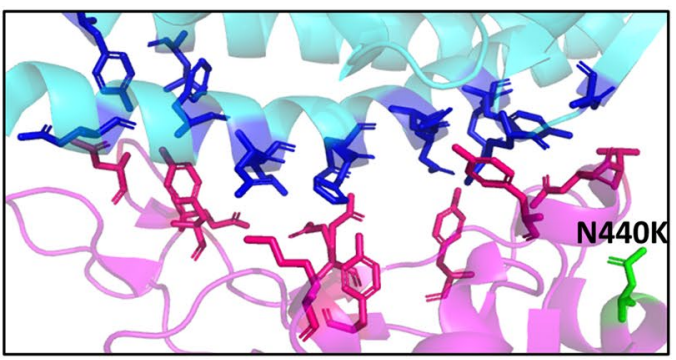

I

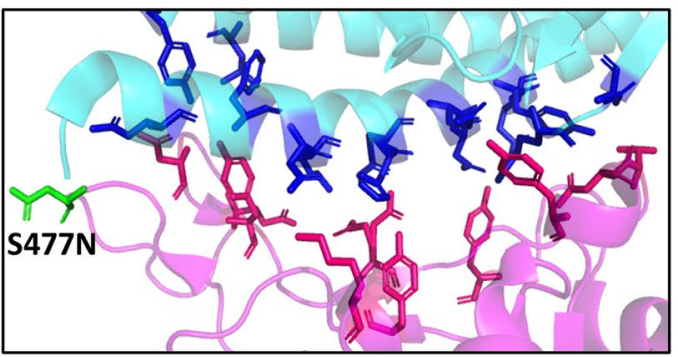

addition to attributes reported for VOI, variants of concern (VOC) cover all new mutations in the virus responsible for increased transmissibility, disease severity associated with increased cases of hospitalizations or deaths, widespread interference with available diagnostic techniques, and decreased effectiveness of available vaccines or therapies [16].

With the escalating lineage turnover of SARS-CoV-2 and no standardized naming system, various nomenclature systems were established by different teams and agencies. The Global Initiative on Sharing All Influenza Data (GISAID), NextStrain, and Phylogenetic Assignment of Named Global Outbreak (Pango) are the most common naming conventions that are being used by the scientific community worldwide to address the SARS-CoV-2 variants [17]. The GISAID system is simple and identifies large clades characterized by major mutations with respect to a reference genome WIV04 (GenBank accession number: MN996528.1) 
Fig. 3 a Cartoon representation of monomeric S protein of SARSCoV-2 (PDB ID: 6XR8) depicting its different subunits where the $\mathrm{S} 1$ subunit is represented in blue, the RBD is shown in magenta, and the S2 is denoted in green color. b Cartoon representation of the S1 subunit (blue) and RBD (magenta) (PDB ID: 6XR8) with their key mutations depicted in the form of red sticks. Labeled and encircled residues represent the important mutations and their location in S1 protein of emerging variants of SARS-CoV-2. c Cartoon representation of the S2 subunit (green) (PDB ID: 6XR8) and its key mutations depicted as red sticks. Labeled and encircled residues represent the important mutations and their location in $\mathrm{S} 2$ protein of emerging variants of SARS-CoV-2 (Color figure online)

but the recurrent, parallel, and backward mutations in the genome led to discrepancies in defining lineages [18]. To overcome this problem, NextStrain devised a system using phylogenetic and phylodynamic analysis to identify evolutionary stable clades and sub-clades [18]. Once identified, the clades are named with the year of emergence as prefix followed by a letter signifying the order in which the clade was identified (For instance, 19A refers to the 1st lineage identified from 2019). The system has certain advantages but some lineage names contain additional information to the name with no systematic rule (like 20E/EU1, 20I/501Y. V1) making the naming inconsistent.

In this article, we have referred to the emerging SARSCoV-2 variants using the Pango nomenclature system [19]. This is a dynamic system which is based not only on the evolutionary relationships but also takes into account the epidemiological relevance of the lineage [18-20]. According to this system, each lineage name consists of an alphabetical prefix and numerical suffixes separated by a period or dot [21]. The alphabetic prefix denotes the parental lineage. Till date two major lineages have been identified, namely, lineage A which is represented by Wuhan/WH04/2020 sequence (GISAID accession id: EPI_ISL_406801) having the same two nucleotides at positions 8,782 in ORF1ab and 28,144 in ORF8 as the bat coronaviruses RmYN02 and RaTG13 and lineage $\mathrm{B}$, which consists of those that have differing nucleotides than lineage $\mathrm{A}$ at similar positions and is defined by the Wuhan-Hu-1 sequence (GenBank accession number: MN908947.3) [19, 21]. The numerical suffix signifies the order in which the descendants of the lineage were identified whereas each period signifies "descendant of" and is used when a new descendent of the lineage can be clearly identified [21]. For instance, B.1.617.1 is the first-named descendant of B.1.617 and in turn, it is the 617th named descendant of lineage B.1 and so on. Although a few other minor lineages have also been recognized like $\mathrm{C}$ and $\mathrm{D}$ which are currently circulating locally [17]. In conclusion, the Pango system provides a detailed and more informative outbreak cluster information while the other two systems are simpler.

Variants of B.1.526, B.1.526.1, B.1.527, and P.2 lineages have been classified under VOI and those belonging to B.1.1.7, B.1.351, B.1.427, B.1.429, B.1.617, and P.1 a
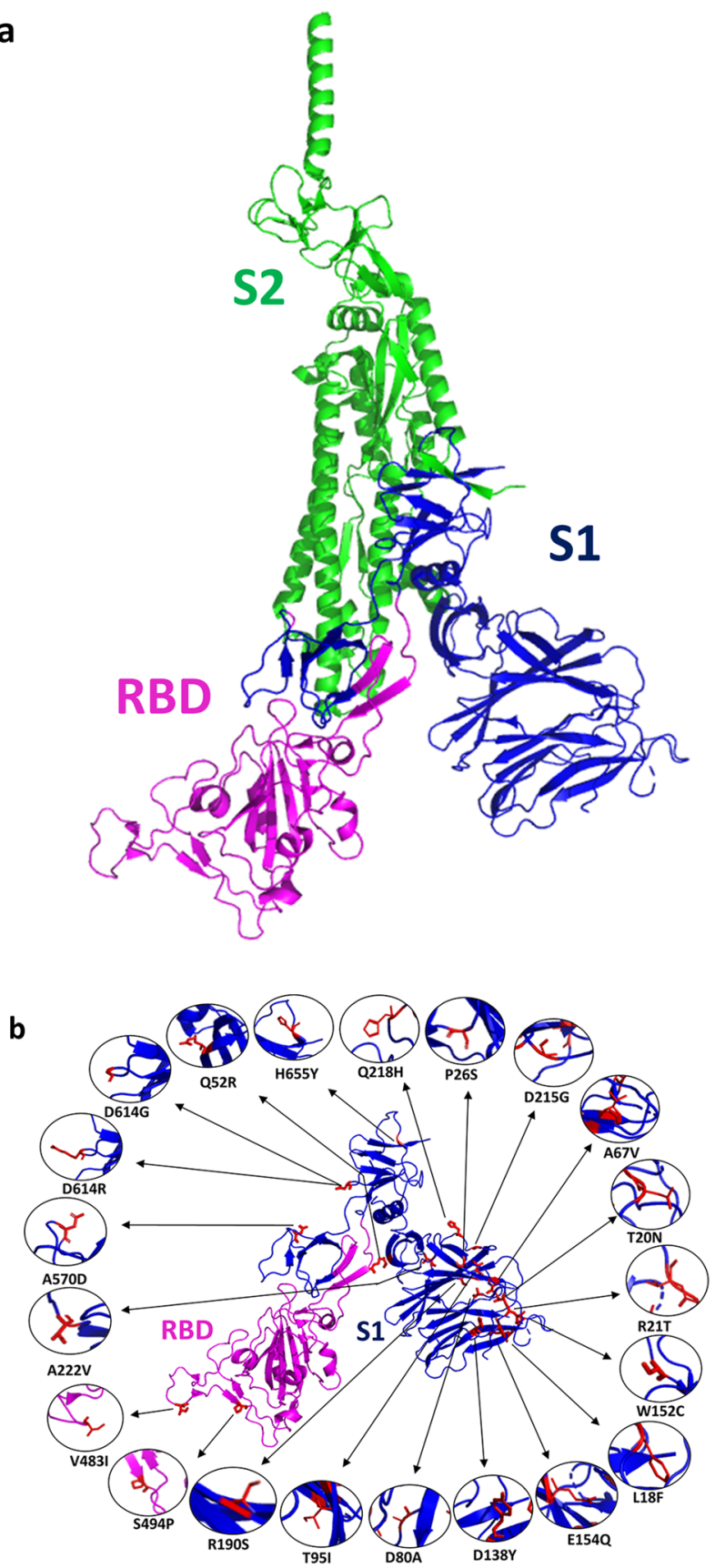

c

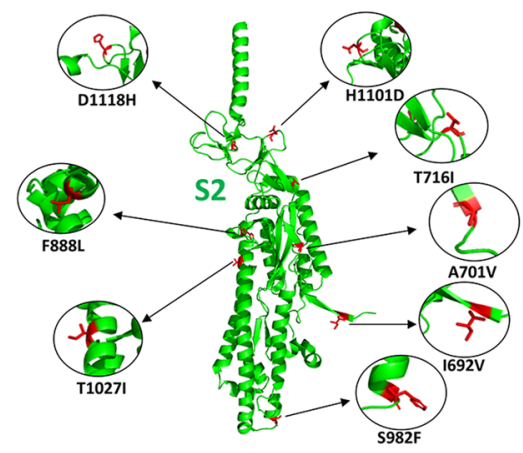


lineages have been categorized under VOC [16]. Covering all attributes of VOC, new mutations leading to a substantial reduction in vaccine efficacy, a higher number of vaccine breakthrough cases, or reduced susceptibility to multiple emergency use authorization (EUA) therapeutics will be categorized under variant of high consequence (VOHC). To date, however, no new variant of SARS-CoV-2 has qualified the criteria of VOHC [16]. Recently, an expert meeting organized by the World Health Organization (WHO) and other health agencies have suggested the use of straightforward Greek alphabets for the VOC and VOI to aid public discussions of variants [22]. Currently, the VOCs B.1.1.7, B.1.351, B.1.1.28, and B.1.617.2 are being referred to as alpha, beta, gamma, and Delta variants respectively while VOI such as B.1.417/B.1.419 are labeled as epsilon, B.1.525 as eta, B.1.617.1 as kappa, and so on [22].

\section{Current Therapeutic and Prophylactic Strategies to Combat SARS-CoV-2}

Antiviral pharmaceuticals and immunotherapies are the main therapeutic and prophylactic approaches currently employed to treat COVID-19. A race for the development of vaccines started soon after the initial spread of the virus and a total of 322 vaccine candidates are currently in clinical trials [23]. Seventeen vaccines have received permission for EUA by National regulatory authorities and a total of 6 vaccines have received permission for full use by WHO [24]. In general, inactivated virus vaccines, adenovirus vector vaccines, nucleic acid vaccines (DNA/RNA), and protein subunit vaccines are the different types of approaches currently used to design vaccines against SARS-CoV-2. BNT162b2 (Pfizer/BioNTech) and mRNA-1273 (Moderna/NIH) are the two non-self-replicating mRNA vaccines approved to treat SARS-CoV-2 infections [25]. Both these vaccines contain a nucleoside-modified RNA (modRNA) that locks the encoded full length viral S protein in its prefusion form, encased/encapsulated in a lipid-nanoparticle formulated shell [26]. Conventional vaccine designing strategy involves the inactivation of virus by deactivating its genetic material using chemicals like beta-propiolactone, formalin etc. However, the inactivated virus will still be able to activate the immune system. Sinopharm (BBIBP), CoronaVac, Covaxin (BBV152) etc., are few examples of inactivated virus vaccines for COVID-19 [25]. Oxford-AstraZeneca (AZD1222/ ChAdOx 1), Sputnik V, Johnson \& Johnson etc., are few adenovirus vector vaccines (containing $\mathrm{S}$ protein encoding gene as immunogen) designed and implemented for the treatment of COVID-19 [25].

The emergence of new variants is presently the greatest threat to existing global vaccination therapy and the efficacy of vaccines against circulating variants is a major challenge to avert this pandemic, which is terrifying for all the affected countries. Soon after the global spread of SARS-CoV-2 infection in 2019, the development of anti-spike antibodybased therapeutics has been at the forefront to control the transmission of this virus. Surface anchored $S$ protein of SARS-CoV-2 recognizes and interacts with the host ACE2, facilitating viral attachment and entry into the cell (Fig. 2a and b) $[12,25]$. To disrupt this interaction or to elicit cellular/humoral responses of the host, neutralizing antibodies, or vaccine-based prophylactics against SARS-CoV-2 are designed mainly to target the $S$ protein, restricting the entry of the virus into the host cell and eventually limiting the viral infectivity or transmission [25]. Neutralizing monoclonal antibodies (mAbs) or a cocktail of antibodies targeted against $\mathrm{S}$ protein, represents a major class of passive immunotherapy against SARS-CoV-2 and more than $50 \mathrm{mAbs}$ are in different stages of clinical trials. Considering recent emergency situation, FDA (Food and Drug Administration) has provided EUA for few mAbs including casirivimab (REGN10933), imdevimab (REGN10987), bamlanivimab (LY-CoV555), and etesevimab (LyCoV016), etc. to control infection and complications of SARS-CoV-2 infections [27].

\section{Notable Mutations in the $\mathbf{S}$ Protein}

Genomic epidemiology of SARS-CoV-2 variants is important to understand phylogenetic relationships, pathogenicity, host-infectivity, viral tropism, and viral transmission dynamics across the world. Lineages independently harboring mutations common with certain VOCs are also being detected across the globe, thus highlighting the phenomenon of convergent evolution [7]. For instance, the lineage B.1.525 carries the E484K mutation common with the P.1 lineage and $\Delta \mathrm{H} 69-\mathrm{V} 70$ and $\Delta \mathrm{Y} 144$ mutations are common with the B.1.1.7 lineage. Some variants of SARS-CoV-2 carry single point mutations (also termed lineage-defining mutations), while some are heavily mutated, possessing multiple substitutions or deletions in their genome [7]. Some noteworthy substitutions in the SARS-CoV-2 genome reported to alter affinity, evasion from the immune system, and adaptability of SARS-CoV-2 are explained in the following sub-sections.

\section{D614G}

This substitution, where an aspartic acid is substituted to glycine at position 614 (D614G) in S protein, was rare before March 2020 but later became a prevalent strain throughout the world after outcompeting other pre-existing subtypes [3, 28]. This substitution is accompanied by three other C-to-T mutations at positions in 241, 3037, and 14,408 that resulted in changes in amino acids in the RdRp [28]. Surprisingly, the 
recently discovered and rapidly spreading variants B.1.1.7 (United Kingdom), B.1.1.28 (Brazil), and B.1.351 (South Africa) harbor this D614G mutation, highlighting the transmission advantage of D614G substitution [3]. D614G substitution asynchronously replaced the SARS-CoV-2 strain initially identified in China and became the dominant form of SARS-CoV-2, circulating across the world [2].

The functional importance of D614G mutations is evidenced in recently published articles suggesting that D614G single residue variant is correlated with a high viral load but not with disease severity [2]. Intriguingly, this substitution is reported to possess higher sensitivity to neutralization towards convalescent human sera or vaccinated sera, highlighting that vaccines containing aspartic acid at position 614 , will continue to be effective against the newly evolved D614G substitution carrying variants [29]. Further studies have highlighted that the viruses containing D614G or a combination of mutations were observed to be more infectious than the reference strain (Wuhan isolate). Additionally, this mutation could affect the glycosylation of viral proteins which would play a significant role in virus-host interactions [2]. Previous studies have also speculated that D614G substitution favors open conformation of $\mathrm{S}$ protein and since residue 614 lies outside the RBD, this mutation does not alter the affinity of $\mathrm{S}$ protein to ACE2 [2]. The S1 subunit dissociates more readily from virus with aspartic acid residue at position 614 than virus having glycine at 614. This suggests that the viral spike protein containing D614 is less stable than G614. Consequently, the enhanced infectivity of D614G substituted variant is speculated to be a result of increased stability of S-trimer rather than better exposed RBD [3]. Also, the distance between residue 614 and 647 backbone atoms is shortened, further stabilizing the C-terminal domain of the protein $[2,30]$. Using in silico predictions, it was reported that D614G substitution resulted in the introduction of an elastase cleavage site other than the furin cleavage site. Protease cleavage at the furin site is observed to be more efficient in the D614G variant when compared with aspartic acid at 614 (Figs. 1c and 3b) [31]. In contrast to it, another group has reported that variants having glycine at 614 were observed to be more resistant to cleavage [32]. Therefore, no conclusions could yet be drawn about how the substitution affects the protein cleavage.

Residue 614 is located at the interface of the S1 and $\mathrm{S} 2$ subunit of $\mathrm{S}$-protein and thus, is not accessible to antibody binding for virus neutralization. This interface is not expected to be a part of a critical epitope for vaccinemediated protection and thus, such variants are unlikely to interfere with vaccine efficacy [33]. In agreement with recently published reports, it is therefore hypothesized that the antibodies acting against S-protein would cross-react with variants containing D614G substitution. Moreover, vaccines could also be redesigned with the D614G insert in the $\mathrm{S}$ protein, since this variant has become dominant worldwide [33]. Owing to the internal location of residue 614 , it is improbable to have D614G variants as a component of neutralizing epitope on $\mathrm{S}$ protein and thus any impact on the efficacy of neutralizing antibodies following vaccination with D614-derived vaccines is very less likely [34].

\section{N439K}

This is the second most commonly observed mutation that was first reported in Scotland and later emerged as B.1.258 lineage, detected in more than 30 countries worldwide [35]. The substitution is reported to be caused by a C-to-A transversion at the nucleotide level. This mutation imparts a twofold increase in binding affinity towards the ACE2 receptor, which eventually confers a fitness advantage to the virus (Figs. 2i and 4) [35]. N439K carrying variants evades antibody-mediated immunity against $\mathrm{mAb}$ and polyclonal antibodies as reported for imdevimab [35].

\section{N440K}

The emergence and re-emergence of SARS-COV-2 variants associated with highly transmissible phenotype is a topic of public health concern as these variants could lead to increased cases of reinfection as well as could adversely affect the efficacy of vaccines. Recent data suggest the widespread occurrence of N440K (also known as B.1.36) mutation in variants worldwide. A rapid increase in the prevalence of $\mathrm{N} 440 \mathrm{~K}$ substitution was observed in March and April 2021 when most of the cases were reported from different states of India [36]. Variants carrying N440K mutation also include a P323L substitution in RdRP and C64F mutation in the membrane glycoprotein (Figs. 2j and 4) [36].

Notably, this substitution is also reported to display resistance to C135 and imdevimab mAbs [4]. Residue N440 forms a strong Hydrogen bond with D54 and a weak hydrogen bond with P52 and R55 residues of the C135 antibody. However, the N440K substitution displays a weak interaction with D54 residue highlighting the possible reason for immune evasion and resistance to neutralizing mAbs, as observed in asymptomatic reinfection cases of this mutant in healthcare workers from India [37]. This substitution also exhibited complete loss of binding to C135 mAbs, but retained binding to $\mathrm{C} 121$ and $\mathrm{C} 144 \mathrm{mAbs}$ [38]. Studies also reported that variants carrying this substitution also possessed enhanced binding affinity to ACE2 [4]. The higher prevalence of this variant in India and its nature of evading host immune response highlights further study of this variant as a topic of public health concern. In another study it 


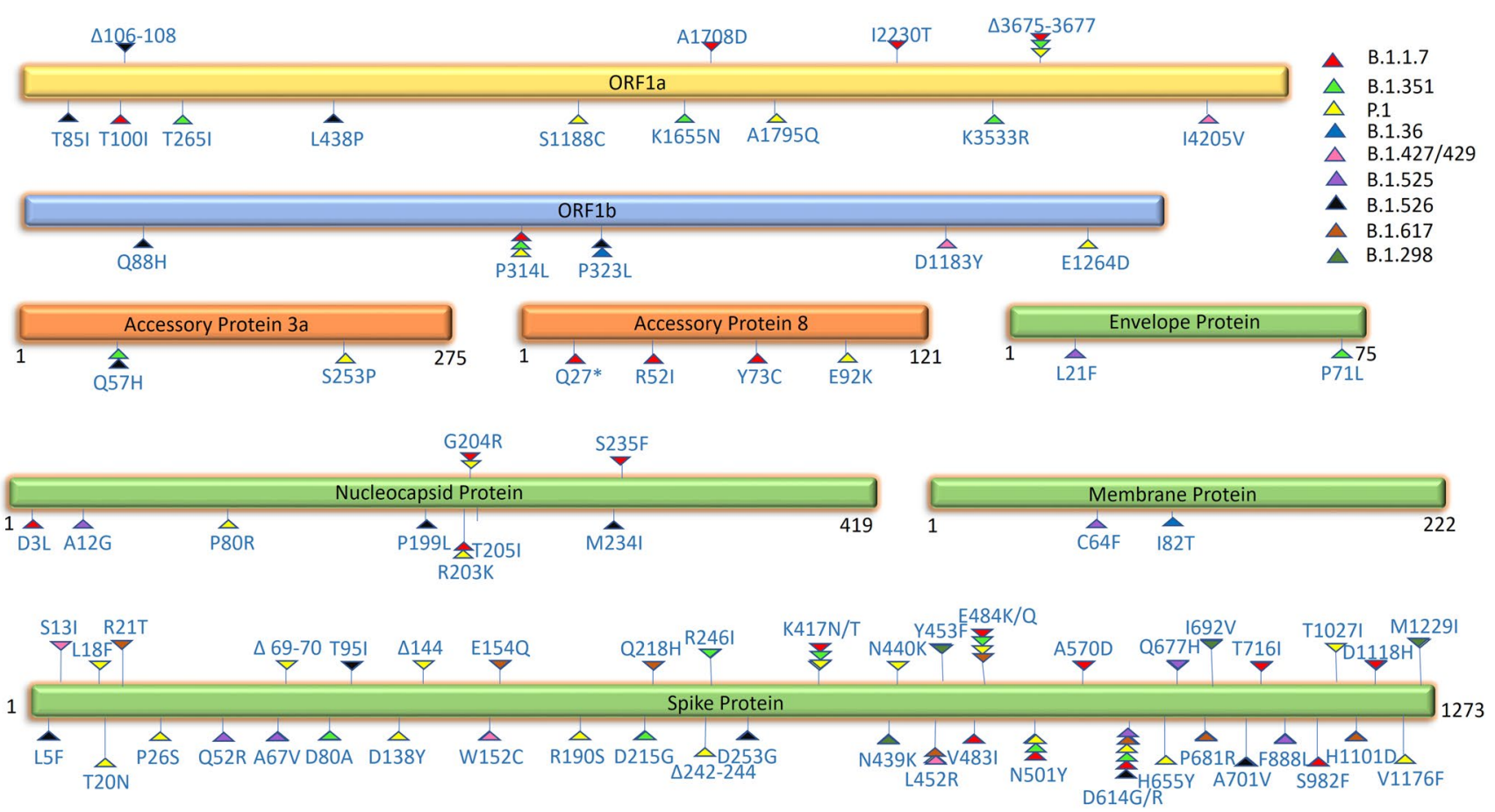

Fig. 4 Novel mutations in SARS-CoV-2 genome across different lineages. Sites of significant mutations in open-reading frames (ORFs), accessory proteins, nucleocapsid protein, membrane protein, envelope

is reported that variant containing $\mathrm{N} 440 \mathrm{~K}$ substitution produces higher titers of infectious virions [36].

\section{Y453F}

Zoonotic or zooanthroponotic transfer of virus is also a significant point of concern raised after cross-species transmission of SARS-CoV-2 into a variety of non-human primates such as farmed minks in the Netherlands that led to a massive culling of animals on affected farms [39]. The spillover of the virus into the mink population is predicted to be associated with recurrent accumulation of mutations in the RBD of S protein. Also known as 'Cluster 5 variant' or B.1.298, variants carrying this substitution involves a total of 5 mutations in the S protein: a deletion at positions H69-V70 and substitutions at Y453F, I692V, and M1229I (Figs. 2, 3, and 4) (Table 1) [39]. Y453F alone or in combination with H69V70 deletions confer an ability to quickly replicate to high titers, and can result in evasion of recognition by neutralizing antibodies [39]. A line of recent studies have addressed the possibility of Y453F substitution in deterring HLAA24-restricted cytotoxic T-lymphocyte (CTL) mediated response [6]. Y453F substitution in combination with other mutations $\Delta \mathrm{H} 69, \Delta \mathrm{V} 70, \mathrm{I} 692 \mathrm{~V}$, and M1229I resulted in significant inhibition of entry into cells, possibly explaining the reason for its lower efficiency in transmission to humans or its quick disappearance shortly after its introduction among protein, and spike protein are marked in form of triangles $(\Delta)$. Color coded triangles are used to represent variants containing these mutations in their genomes (Color figure online)

human population [39]. In addition to it, the variants carrying this mutation display more sensitivity to inhibition by soluble ACE2, as the residue is located in RBD of S protein, and this substitution is reported to increase binding affinity ACE2 in humans (Figs. 2 and 4) [39]. The lower prevalence of this variant in the human population suggests that the candidate mutations are not expected to increase transmission of the virus [40].

The neutralization potential of casirivimab was considerably reduced because of Y453F substitution. Intriguingly, imdevimab is documented to inhibit $\mathrm{S}$ protein driven entry with high efficiency [39]. As expected, a cocktail of both casirivimab and imdevimab mAbs is reported to block SARS-CoV-2 variants containing this mutation quite efficiently [39]. Conversely, Y453F substitution diminished neutralization or inhibition of viral entry by convalescent plasma/sera derived from recovered COVID-19 patients [39].

\section{A222V}

Variant B.1.177 (20E.EU1) is characterized by A222V substitution and was first reported in Spain, which later became prevalent in more than $65 \%$ of all sequenced genomes in England in November 2020 [41]. A222V substitution is located away from the RBD of S protein but is a part of the 
Table 1 Comparison of mutations in new variants of SARS-CoV-2 with their effect on current preventive and therapeutic strategies

\begin{tabular}{|c|c|c|}
\hline Variant & Mutation & Effects \\
\hline B.1.1.7 [51, 104] & $\begin{array}{l}\text { S protein: } \Delta H 69, \Delta V 70, \Delta Y 144, \text { V483I, N501Y, } \\
\text { A570D, P681H, T716I, S982A, and D1118H } \\
\text { ORF1a: T100I, A1708D, I2230T, } \Delta \text { S3675, G3676, and } \\
\text { F3677 } \\
\text { ORF1b: P314L } \\
\text { N Protein: D3L, R203K, G204R, and S235F } \\
\text { ORF8: Q27*, R52I, Y73C }\end{array}$ & $\begin{array}{l}\text { - Failure of current diagnostic techniques } \\
\text { - Increased transmissibility and infectivity } \\
\text { - Modest reduction in neutralization efficacy of antibod- } \\
\text { ies targeting NTD of S protein } \\
\text { - No effect on efficacy of antibodies targeting RBD of S } \\
\text { protein } \\
\text { - Increased mortality rate }\end{array}$ \\
\hline B.1.351 $[51,68,70]$ & $\begin{array}{l}\text { S Protein: D80A, D215G, } \Delta \mathrm{L} 242, \Delta \mathrm{A} 243, \Delta \mathrm{L} 244, \\
\text { K417N, E484K, N501Y, D614G, and A701V } \\
\text { ORF1a: T265I, K1655N, K3353R, } \Delta \text { S3675, } \Delta \mathrm{G} 3676, \\
\text { and } \Delta \mathrm{F} 3677 \\
\text { ORF1b: P314L } \\
\text { ORF3a: Q57H } \\
\text { N Protein: T205I } \\
\text { E Protein: P71L }\end{array}$ & $\begin{array}{l}\text { - Enhanced transmissibility } \\
\text { - Improved binding affinity for ACE2 receptor } \\
\text { - Escape from neutralization by convalescent sera } \\
\text { - Decreased efficacy of vaccines }\end{array}$ \\
\hline P.1 [51] & $\begin{array}{l}\text { S protein: E484K, N501Y, K417T, L18F, T20N, P26S, } \\
\text { D138Y, R190S, H655Y, T1027I, and V1176F } \\
\text { ORF3a: S253P } \\
\text { ORF1a: S1188L, K1795Q, } \Delta \text { S3675, } \Delta \text { G3676, and } \\
\text { AF3677 } \\
\text { ORF1b: P314L, E1264D } \\
\text { N protein: P80R, R203K, and G204R } \\
\text { ORF8: E92K }\end{array}$ & $\begin{array}{l}\text { - Higher transmissibility } \\
\text { - Improved affinity for ACE2 receptor } \\
\text { - Resilient to convalescent sera and vaccines } \\
\text { - Immune escape }\end{array}$ \\
\hline B.1.617.1 $[23,81]$ & $\begin{array}{l}\text { S protein: R21T, T95I, G142D, E154K, Q218H, } \\
\text { L452R, E484K, D614G, P681R, Q1071H, and } \\
\text { H1101D }\end{array}$ & $\begin{array}{l}\text { - Improved transmissibility } \\
\text { - Reduced neutralization efficacy of RBD-directed mAbs } \\
\text { - Escape from (HLA)-24-restricted cellular immunity }\end{array}$ \\
\hline B.1.617.2 [23, 81] & $\begin{array}{l}\text { S protein: T19R, D111D, G142D, } \Delta 156, \Delta 157, \mathrm{R} 158 \mathrm{G}, \\
\text { E484Q, L452R, D614G, P681R, and D950N }\end{array}$ & $\begin{array}{l}\text { - Reduction in neutralization efficacy of vaccines and } \\
\text { convalescent sera }\end{array}$ \\
\hline B.1.36 [36] & $\begin{array}{l}\text { S protein: } \mathrm{N} 440 \mathrm{~K} \text { and } \mathrm{D} 614 \mathrm{G} \\
\text { ORF1: P323L } \\
\text { M protein: } \mathrm{C} 64 \mathrm{~F}\end{array}$ & $\begin{array}{l}\text { - Variant of Immune escape } \\
\text { - Enhanced binding affinity to host cell receptor ACE2 } \\
\text { - Rapid spread and higher infectious fitness }\end{array}$ \\
\hline B.1.427 \& B.1.429 $[5,104]$ & $\begin{array}{l}\text { S protein: S13I, W152C, and L452R } \\
\text { ORF1a: I4205V } \\
\text { ORF1b: D1183Y }\end{array}$ & $\begin{array}{l}\text { - } 20 \% \text { increase in transmission frequency } \\
\text { - Increased binding affinity of virus to ACE2 receptor } \\
\text { - Reduction in neutralization potency of RBD-directed } \\
\text { mAbs } \\
\text { - Complete loss in neutralization efficacy of NTD- } \\
\text { specific mAbs } \\
\text { - Protects the variant from humoral and HLA-restricted } \\
\text { cellular immunity }\end{array}$ \\
\hline B.1.525 [92] [95] & $\begin{array}{l}\text { S protein: Q52R, A67V, } \Delta 69 / 70, \Delta 144, \mathrm{E} 484 \mathrm{~K}, \\
\text { D614G, Q677H, and F888L } \\
\text { E protein: } \mathrm{L} 21 \mathrm{~F} \\
\text { M protein: } \mathrm{I} 82 \mathrm{~T} \\
\text { N protein: A12G }\end{array}$ & $\begin{array}{l}\text { - Potentially reduced vaccine efficacy } \\
\text { - Potentially reduced neutralization by vaccine sera } \\
\text { - Enhanced binding to ACE2 receptor }\end{array}$ \\
\hline B.1.526 $[92,95]$ & $\begin{array}{l}\text { S protein: L5F, T95I, D253G, E484K, S477N, D614G, } \\
\text { and A701V } \\
\text { ORF1a: } \Delta 106-108, \text { T85I, and L438P } \\
\text { ORF1b: P323L and Q88H } \\
\text { ORF3a: Q57H } \\
\text { N protein: P199L and M234I }\end{array}$ & \\
\hline B.1.298 [6] & $\begin{array}{l}\text { S protein: } \Delta \mathrm{H} 69 \& \Delta \mathrm{V} 70, \mathrm{Y} 453 \mathrm{~F}, \mathrm{D} 614 \mathrm{G}, \mathrm{I} 692 \mathrm{~V} \text {, and } \\
\text { M1229I }\end{array}$ & $\begin{array}{l}\text { - Increased affinity for ACE2 receptor of humans } \\
\text { - Mink-specific adaptation for cross-transmission } \\
\text { - Resistance to antibody neutralization and convalescent } \\
\text { plasma } \\
\text { - Escape from HLA-A2A-mediated cellular immunity }\end{array}$ \\
\hline
\end{tabular}

* Stop codon

$\Delta$ Deletion mutation 
NTD which is presumably playing a direct role in receptor binding or membrane fusion (Figs. 3b and 4) [42]. This mutation is characterized by additional non-synonymous mutations, V30L (ORF10), A220V (N protein), and L67F (ORF14) [43].

\section{S477N}

Prevalent in 20A.EU2 lineage and the hallmark mutation of Marseille-4 variant, this mutation arose independently in Australia [44]. Since the mutation is located in RBD, it is reported to slightly increase its binding affinity with ACE2 receptor and confers a modest increase in infectivity (Fig. 2l) [44]. Moreover, substitution at S477N imparts broad-spectrum resistance against antibody-based therapeutics and convalescent sera. Other additional non-synonymous mutations associated with S477N include M234I and A376T in the N protein; A176S, V767L, K1141R, and E1184D in ORF1b [44]. No decrease in neutralization potency was observed when treated with casirivimab and imdevimab [45].

\section{S494P}

The mutation imparts a higher binding affinity towards ACE2 receptor attributed to strong interfacial complementarity associated with it (Figs. 2b, 3b, and 4) [46]. This substitution makes it an escape variant causing a 3 to fourfold diminution in neutralization from convalescent sera and decreased neutralization efficacy of mAbs [47, 48]. Interestingly, bamlanivimab and etesevimab cocktail is observed to be ineffective against this escape mutation [49].

\section{Currently Circulating Variants of SARS-CoV-2}

\section{Variants of Concern (VOC)}

\section{B.1.1.7}

This lineage, first reported in England, was later placed in the category of VOC (VOC 202012/ 501Y.V1) in December 2020 [16]. This variant has been registered in more than 30 countries, primarily in UK, South Africa, and Brazil [50]. The variant accrues seven non-synonymous mutations and three deleterious mutations in its $S$ protein (Table 1) [51]. Notably, the substitution of asparagine to tyrosine at 501 positions (N501Y) in RBD of the S protein is the sole mutation impeding the interaction of $S$ protein with ACE2 (Figs. $2 \mathrm{~g}$ and 4). Intriguingly, the substitution of proline to histidine at position $681(\mathrm{P} 681 \mathrm{H})$ immediately adjacent to the furin cleavage site (Fig. 1c) is reported to significantly impact the infectivity and transmissibility of this variant [52]. To address further, H69/V70 deletion in S protein is primarily attributed to the failure of current diagnostic techniques such as real-time reverse transcription-polymerase chain reaction (RT-PCR) and antigen detection assays to detect the presence of virus precisely [50]. In addition, recent findings suggest that deletion of Y144 is reported to circumvent neutralization by RBD-specific mAbs including S2M28, S2X28, S2X333, and 4A8 [26, 53].

Concordantly, D614G, V483I, A570D, T716I, S982A, and $\mathrm{D} 1118 \mathrm{H}$ are few other mutations located in its $\mathrm{S}$ protein (Table 1) (Figs. 3b, c, and 4) [54]. Evidently, there was no change in disease burden but the mortality rate was increased by $35 \%$, and the reinfection rate was observed to be $0.7 \%$ higher than the reference strain $[55,56]$. Pertinent to these observations, the variant is estimated to be more infectious with an estimated high reproduction number of $\sim 90 \%$, which suggests that people infected with this variant are more infectious than those infected with any other pre-existing variant [57]. This variant also displayed an intensified transmission rate of $\sim 43-90 \%$ as determined by various statistical and dynamic modeling studies, but the disease severity remained unchanged in infected individuals [58]. Multiple studies have reported the susceptibility of this variant to convalescent plasma and vaccine sera, suggesting a modest reduction in neutralization titer, although there is no evidence of vaccine escape [59]. This variant is refractory to neutralization by mAbs targeting the NTD of S protein, however, no significant reduction in neutralization efficacy was observed for antibodies designed or targeted against RBD of S protein [23]. In another study, the activity of only two RBD-targeted mAbs 910-30 and S309 out of 12, was markedly compromised [60]. Both the Pfizer and Moderna vaccines were also found to be as effective as they were on the reference strain and displayed only a slight reduction in neutralization efficacy [23, 26]. Similarly, AstraZeneca vaccine also displayed slight reduction in neutralization activity against this variant when compared with the Wuhan isolate, but the overall clinical vaccine efficacy for this variant was 70.4\% [23]. IgM-14, an IgM neutralizing antibody, is recently reported to neutralize this variant [61]. Sera of patients immunized with Covaxin is documented to neutralize this variant, discounting the probability of neutralization escape [23]. Some of the sub-variants of B.1.1.7 lineage are reported to harbor another important mutation in RBD, i.e., substitution of glutamic acid to lysine at 484th amino acid (E484K), that is presumably linked with reduced virus neutralization by plasma (Figs. 2c and 4) [50].

\section{B.1.427 and B.1.429}

By the end of 2020, another novel SARS-CoV-2 VOC, B.1.427/429 (also known as CAL.20C or L452R) gained momentum and became predominant in the USA [6]. Collectively, analysis of the rapid and progressive spread of this 
variant from the US to other countries suggested its greater transmissibility rate relative to currently circulating strains of SARS-CoV-2. Both of these lineages share a triad of coding mutations in S protein (S13I, W152C, and L452R) that are not found in other reported VOCs (B.1.1.7, B.1.351, and P.1) (Table 1) [5].

Unlike N501Y variants, residue L452 does not interact directly with the ACE2 receptor but it is highly plausible that the L452R substitution induces structural changes in the protein, enhancing the interaction between $\mathrm{S}$ protein and ACE2 receptor and providing it an adaptive advantage (Figs. 2b, k, and 4). It is also plausible that S13I and W152C substitutions may contribute to alleviated infectivity of this variant $[5,6]$. L452R mutation results in a higher free binding energy of SARS-CoV-2:ACE2 complex, leading to a stronger attachment between host cell receptor and virus [7]. L452R substitution in B.1.427/B.1.429 variants, not only enhances affinity of the virus to ACE2, but is also reported to increase the protein stability, viral infectivity, and enhanced rate of viral replication [6]. Interestingly, L452R or Y453F substitution protects the variants from both humoral and HLA-restricted cellular immunity, suggesting an increased immune evasion that could further deteriorate the pandemic situation $[6,62]$. A negligible effect on $\mathrm{CD}^{+}$and $\mathrm{CD} 8^{+}$ mediated T-cell responses was observed for this variant and the vast majority of $\mathrm{CD} 8^{+} \mathrm{T}$-cell epitopes are unaltered by these mutations [62].

The average neutralization efficacy of Moderna-elicited plasma was reduced 2.8-fold for B.1.427/B.1.429 variants as compared to the prototypic Wuhan-1 isolate, whereas the potency was abridged fourfold when treated with Pfizerelicited plasma [63]. Sensitivity to RBD and NTD-specific mAbs was also reported, where 14 out of $35 \mathrm{mAbs}$ showed a reduction in neutralization efficacy of B.1.427/B.1.429 variants possibly due to central location of L452R residue in epitopes detected by these mAbs [63]. Bamlanivimab resulted in a complete loss of its neutralization potency against this variant, whereas a small reduction was observed for regdanvimab (CT-P59) and etesevimab mAbs. A cocktail of bamlanivimab and etesevimab is reported to perform better than monotherapy against this variant [64]. Contrary to this, a combination of casirivimab and imdevimab or COV2130 and COV2196 have shown no loss in neutralization potency against all VOCs including B.1.427 and B.1.429 [65]

One broad-spectrum coronavirus antibody, VIR-7831 is effective against these widely circulating VOCs [64]. Neutralization action of casirivimab/imdevimab cocktail and VIR-7831 mAb which was recently reported to provide $85 \%$ protection against COVID-19 related hospitalization and deaths, was unaffected by L452R mutation [63]. Not only this, the neutralization efficacy of all NTD-specific mAbs was abolished due to S13I and W152C mutations [63].
Furthermore, S13I mutation led to shifting of signal peptide cleavage site after deletion of Q14 and C15 residues of the $\mathrm{S}$ protein. This resulted in disruption of the disulfide bond between $\mathrm{C} 15 / \mathrm{C} 136$ that is reported to link the N-terminus to the rest of the NTD, thereby imparting an unusual neutralization-escape ability to B.1.427/B.1.429 [63]. LY-CoV1404, another $\mathrm{mAb}$ targeting the RBD, retained full neutralization efficacy against VOCs namely B.1.1.7, B.1.351, P.1, B.1.526, B.1.427, and B.1.429 [66]. A broadly neutralizing antibody DH1047 targets RBD and neutralizes SARS-CoV, SARS-like bat viruses RsSHC014 or SARS-CoV-2 variants such as D614G, B.1.1.7, B.1.429, and B.1.351 [67].

\section{B.1.351/501Y.V2}

Another highly transmissible VOC of SARS-CoV-2 (B.1.351/501Y.V2) containing multiple S protein mutations was detected in South Africa. Because of the co-occurrence of other non-synonymous mutations in the RBD along with the N501Y mutation, this variant is considered highly transmissible due to the rapidity with which it became dominant variant within weeks and a major contributor to the second wave of infections in South Africa [68].

This variant shares some mutations with B.1.1.7 lineage including N501Y and D614G (Figs. 2g, 3b, and 4). Along with these mutations, D80A, $\Delta$ L242, $\Delta$ A243, $\Delta$ L244, D215G, R246I, K417N, E484K, D614G, and A701V are other signature mutations described in the literature for this variant (Table 1) (Figs. 2, 3b, c, and 4) [69]. As N501Y and E484K substitution confer enhanced affinity for ACE2 receptor, a combination of these mutations are believed to play a role in enhancing its binding affinity (Fig. 2c and g) [70]. Due to the mutations in key residues of RBD, there are significant concerns that the conformational changes in $S$ protein may influence the overall efficacy of vaccines and neutralizing antibodies designed previously based on earlier SARS-CoV-2 strains [71]. Substitution of arginine to isoleucine at position 246 (R246I) and the deleterious mutation cluster $\Delta$ L242-244 in the NTD (Fig. 4), are reported to be responsible for conferring immunity against most NTDdirected neutralizing antibodies [72].

In a recent study, the AstraZeneca vaccine was found to be rather ineffective (10\% efficacy) against mild to moderate cases caused by this variant, and a similar effect was reported for Ad26.COV2.S vaccine [23]. K417N, E484K, and N501Y substitutions along with other mutations in 501Y.V2 strain makes it totally resistant to neutralization by bamlanivimab, CA1, etesevimab, CC12.1, and casirivimab mAbs, and most importantly to convalescent plasma therapies, rendering these therapies ineffective [23, 68, 69]. Neutralization effect of imdevimab was unaffected by this variant and a minimal effect was observed on the neutralization efficacy of AstraZeneca pair AZD106 and AZD8895 
[73]. Sera collected from participants immunized with Moderna vaccine displayed a 2.7 -fold decrease in neutralization efficacy towards this variant [23]. Sera from human subjects immunized with the Pfizer vaccine also exhibited a reduction in neutralization efficacy against it $[23,58]$. BBIBP-CorV an inactivated virus vaccine, and ZF2001, a recombinant dimeric RBD protein vaccine, are highly efficacious against this variant and are capable of effectively neutralizing the virus [74]. The NVX-CoV2373 vaccine also induced notable cross-protection against it [23].

\section{B.1.1.28}

VOC 202101/02 (VOC-202101/02), also known as B.1.1.28 or 20J/501 Y.V3 was first identified in Brazil, later on two more sub-clades designated as P.1 and P.2, were reported from Rio de Janeiro and Manaus, respectively [75]. These variants share key RBD mutations with other VOCs, B.1.351 and B.1.1.7, including a trio of E484K, N501Y, and K417T that are predicted to promote immune escape and affinity towards ACE2 receptor (Figs. 2c, e, and g) [76]. These mutations result in effects similar to other VOCs, rendering the strain resistant to prevalent treatments and preventive measures. Genomic surveillance data and mathematical modeling results suggested that the virus is 1.7-2.4 times more transmissible [77]. Higher transmissibility, reduction in neutralizing efficacy of convalescent sera or vaccines, and higher reinfection rates are the key features for this VOC [51].

Moreover, the other mutations in the $\mathrm{S}$ protein that are unique to this variant like L18F, T20N, P26S, D138Y, R190S, H655Y, T1027I, and V1176F resulted in a variant more resistant towards neutralization (Table 1) (Figs. 3b, c, and 4) [51,77]. Data from another study suggests that there was a sixfold reduction in neutralizing capacity of convalescent plasma and plasma from CoronaVac immunized recipients [78]. Furthermore, the variant has been reported to be highly resistant to mAbs like etesevimab, casirivimab, and bamlanivimab and partially resistant to imdevimab [16, 79]. Pfizer vaccine displayed a 6.7-fold reduction in neutralizing potency for P.1 variants against vaccinated individuals whereas a 4.5-fold reduction in neutralization potency was reported for the Moderna vaccine [23].

\section{B.1.617.2}

The variant B.1.617 that emerged during February 2021 in India, has caused a ferocious second wave of COVID-19, resulting in a bigger outbreak. Recently, B.1.617.2 or the Delta variant became dominant in India and the UK, and was declared a new VOC by WHO (previously classified as VOI) [80]. This lineage consists of many variants including the Delta plus variant (AY.1 and B.1.617.2.1), all of which emerged during October 2020 to February 2021. Each of these variants has a cluster of signature mutations D111D, G142D, L452R, E484Q, D614G, and P681R in their S protein (Figs. 2, 3b, and 4) [81]. E484Q was identified in most of the members of this lineage except in B.1.617.2 [51]. $\mathrm{K} 417 \mathrm{~N}, \mathrm{~V} 70 \mathrm{~F}$, and $\mathrm{W} 258 \mathrm{~L}$ are three mutations exclusively reported in Delta plus variant with a prevalence rate of $\sim 58 \%$ [82].

The variant is known to display 8 mutations, seven of which are in the S1 region; R21T, E154K, and Q218H in the NTD, L452R and E484K in the RBD, D614G and P681R (near the furin cleavage site) and one H1101D in the S2 region (Table 1) (Figs. 1c, 2, 3b, and c) [81]. The sub-lineage mutant B.1.617.1, apart from the common mutations, also has T95I, G142D, E154K, and Q107H in its S protein (Figs. 3b and 4). Another member of the family, B.1.617.2, has T19R, G142D, $\Delta 156, \Delta 157$, and R158G mutations in the NTD region, $\mathrm{L} 452 \mathrm{R}$ and T478K mutations in the RBD region, P681R (close to furin cleavage site), and D950N in the $\mathrm{S} 2$ region of its $\mathrm{S}$ protein (Table 1) (Figs. 3b and 4) [83]. P822L, A446V, V149S, and T181I are four mutations exclusively reported in Delta plus variant only [82].

Structural analysis of the effect of RBD mutations L452R and $\mathrm{E} 484 \mathrm{Q}$ revealed that there was a decrease in intermolecular and intramolecular interactions with ACE2 receptor in comparison to the wild type. The replacement of hydrophobic residue L452 with hydrophilic 452R is predicted to aid in the overall stabilization of the complex. Similar to B.1.426/B.1.427 lineage, substitution of L452R abolishes neutralizing activity of RBD-directed $\mathrm{mAbs}$ and helps in escape from HLA-24-restricted cellular immunity [6, 81]. Intriguingly, another hallmark mutation of Delta variant, the P681R (Fig. 4), located adjacent to the furin cleavage site (Fig. 1c) enhances the basicity of the poly-basic stretch and is presumed to be linked with the efficient fusion of membranes, internalization, and consequently, better transmissibility [81, 84]. Reduced sensitivity of Delta variant towards neutralizing antibodies and increased replication fitness has contributed in replacement of pre-existing B.1.1.7 or other variants by Delta variant. In addition to it, a higher proportion of cleaved spike protein was observed for this variant in comparison to B.1.1.7, and this can presumably be a reason for an increased infectivity rate [85].

Evaluation of efficacy of Pfizer vaccine against B.1.617.2 variant suggested that the vaccine was able to confer $88 \%$ protection against infection of this variant whereas AstraZeneca vaccine displayed 60\% efficacy [23]. Heterologous prime-boost vaccination with Pfizer/AstraZeneca vaccines resulted in a strong immune response against Delta variant with an overall increase in titer (ninefold) of neutralizing antibodies in sera [86, 87]. Interestingly, homologous primeboost vaccination with Pfizer vaccine also resulted in $\sim$ ninefold increase in titer of neutralizing antibodies, producing a strong immune response against the circulating Delta variant 
$[86,87]$. Neutralizing antibodies in COVID-19 recovered individuals with either one or two-dose of AstraZeneca vaccination provided higher protection against Delta variant, in comparison to individuals with only one/two doses of vaccination [88]. Neutralization efficacy of bamlanivimab was completely lost against B.1.617.2 variant, whereas casirivimab, imdevimab, and etesivimab were still active against it. A twofold reduction in neutralization efficacy of convalescent sera from COVID-19 recovered patients and recipients of Covaxin, was reported for this variant $[89,90]$. Details of its transmissibility, immune escape, efficacy of vaccines, or therapeutic treatments are still not reported and further studies are required for its complete characterization.

\section{Variants of Interest (VOI)}

\section{B.1.525 and B.1.526}

Recent months have seen numerous surges and prevalence of new SARS-CoV-2 VOIs, B.1.525 and B.1.526 harboring the E484K mutation in the S protein (Table 1). First identified as a geographically dispersed cluster in UK in 2021, the variant B.1.525 was identified and designated as VUI202102/03 (previously designated as UK1188) in New York state [91]. Since its first detection, E484K substitutions in B.1.525/B.1.526 emerged as the most frequently identified $S$ protein mutation (Figs. 2c and 4), with an observed 26-fold increase in amount of circulating virus (reported within a month), making it as a topic of immediate global health concern [91]. B.1.526 lineage comprises two sub-lineages harboring S477N or characteristic E484K S protein mutations (Figs. 2c, 1, and 4) [92]. Variant B.1.526 is characterized by substitutions in the $\mathrm{S}$ protein, including L5F, T95I, D253G, D614G, and A701V, whereas the hallmark mutations reported for B.1.525 variant comprises primarily of Q52R, A67V, $\Delta 69 / 70, \Delta 144$, E484K, D614G, Q677H, and F888L in S protein (Table 1) (Figs. 3b, c, and 4).

Along with R246I, D253G substitution may contribute to antibody neutralization escape by an important neutralization epitope. $\mathrm{S} 477 \mathrm{~N}$ substitution is reported to be associated with the increasing viral infectivity because of increased binding affinity for ACE2 receptor or by exhibiting resistance to neutralizing antibodies [93]. T95I is a buried residue in NTD and does not seem to affect antigenicity. Moreover, $\mathrm{T}$ to I substitution is not close to RBD of adjacent subunits in homotrimer, hence, does not influence the close-to-open transition of RBD [91]. Preliminary data suggest that the variant B.1.526 is neither associated with increased severity of the disease, nor is found to be linked with breakthrough infections (infection after vaccination) or reinfection [94]. Q677H substitution is located near the furin cleavage site (Figs. 1c and 4). However, the impact of this mutation is not yet determined, it is only hypothesized that the mutations around the furin cleavage site can alter transmissibility. Deletion of 144 (Fig. 4) is an antigenic escape mutation and is highly associated with virus replication in immunocompromised patients [95].

Ly-CoV1404, an ACE2-blocking antibody, is reported to completely neutralize variants including B.1.526 [66]. Neutralization titer of sera against $\mathrm{E} 484 \mathrm{~K}$ variant was decreased by 3.6-fold when serum sample of Pfizer-vaccinated patient was used, whereas serum derived from vaccinated individual showed $\sim 3$.4-fold lower efficacy on $\mathrm{S} 477 \mathrm{~N}$ variant. Interestingly, serum from individuals administered with the Moderna vaccine also displayed a similar effect against both the variants [96]. In another study, E484K substitution exhibited a moderately increased resistance to neutralization to both Pfizer-vaccinated sera or convalescent sera [97]. Imdevimab completely neutralized the B.1.526 isolate. Casirivimab, when tested against both E484K and S477N variants, resulted in complete neutralization of the S477N variant but was observed to be 12 -fold less active against E484K B.1.526 variant [96]. A cocktail of casirivimab and imdevimab completely neutralized the B.1.526 variant and a partial loss in neutralization potency was observed for B.1.526 variant containing E484K substitution [96].

\section{Conclusion}

While 2020 presented an extraordinary challenge to mankind, 2021 appeared to be a more unpredictable and difficult phase with the advent of multiple variants of SARSCoV-2 displaying increased transmissibility and infectivity. The continuous evolution of SARS-CoV-2 since its initial appearance and the persistent emergence of new variants have instigated rapid progress in sequencing efforts to characterize genome, evolutionary history, and geographical spread of the virus. Like other coronaviruses, SARS-CoV-2 has an evolutionary genetic proofreading mechanism due to the presence of nsP14 displaying $3^{\prime}-5^{\prime}$ exoribonuclease activity [2]. Coronaviruses have a slightly low mutation rate (2 nucleotides/month) in comparison to many other RNA viruses such as influenza virus (4 nucleotides/month) and HIV (8 nucleotides/month), due to the existence of 'proofreading enzyme' that fixes its fatal copying errors [9]. In spite of proofreading capability that yields high replication fidelity, new mutations are being accumulated in genome of SARS-CoV-2, as is clearly evidenced from emerging variants [98]. Biochemical makeup of different cell types or cells from different hosts can presumably be one reason for replication associated random mutations, as the quantity or quality of substrate required by the viral polymerase for its catalytic activity may vary between different cell types or in different hosts [99]. Recombination events, host immunity, 
and host factors such as interactions with different orthologs of TMPRSS receptors among different species, also exerts a selective pressure on the virus [99].

The unprecedented frequency of generation of new SARSCoV-2 variants has resulted in the accumulation of new mutations throughout the viral genome, including $\mathrm{S}$ protein, nucleocapsid, ORF1a, ORF1b, ORF3, and ORF8 (Figs. 1, 2, 3b, c, and 4) [100]. Not only the tremendous frequency of spread of new mutants globally, but also their co-circulation in endemic areas has led to speculation that virus spillover has led to the emergence of 'fit' variants perhaps due to poor accuracy of its genomic replication [101]. For better adaptation to host, the $\mathrm{S}$ protein of SARS-CoV-2, responsible for mediating entry into the host cell, has undergone several mutations that has contributed to enhance viral infectivity [2], transmission rate [16], evasion from the immune system of host cell, crossspecies transmission, and ability to show infections in young population (Table 1) (Figs. 2, 3, and 4) [9].

In response to the urgent need for an effective preventive measure to control the spread of SARS-CoV-2, vaccinebased therapies have been developed by several countries that are selectively designed for targeting the $\mathrm{S}$ protein. The observed frequency of new mutations in the $S$ protein of emerging variants has created a stressful situation as the variants may not only jeopardize the vaccine-based countermeasures but also can deceive diagnostic approaches leading to false-negative results. Certain in vitro diagnostic techniques such as immunoassays and RT-PCR may fail to produce precise results if the mutation occurs in an area specific for antibody or primer binding. As additional mutations are reported in S protein, there is a high likelihood that immunoassays designed to detect $\mathrm{S}$ protein may become more susceptible to produce false results. For efficient diagnosis of SARS-CoV-2 virus and its emerging variants, immunoassays such as enzyme-linked immunosorbent assay (ELISA) or lateral flow assay (LFA) could be re-designed that would rely on polyclonal antibodies instead of mAbs and would work after recognizing multiple epitopes on virus [9].

Based on available sequencing data, many new variants are not completely characterized and their effects on transmission rate or immune evasion are not studied. Detailed and continuous update of novel variants is extremely important for the serosurveillance and phylodynamic analysis to continuously monitor the trend of infection in population and assessment of the potential impact of epidemiological or evolutionary processes in shaping viral phylogenies. Failure of current diagnostic approaches against newly emerging variants of SARS-CoV-2 is also an important topic of concern that will be required to be monitored continuously in the following years since the mutations can rapidly become predominant in new variants with natural selection or for better adaptation in host and can lead to more threatening waves of COVID-19. A multi-target strategy can be designed and implemented to minimize the effect of SARS-CoV-2 on the immune system of host or diagnostic assays. With the initiation and successful rollover of vaccination programs in different countries, the efficacy of vaccines against new variants of SARS-CoV-2 is a topic of concern as cases of reduced efficacy against few variants have also been consistently observed. Since vaccines take a long time to develop, redesigning available vaccines can also be considered a tangible alternative. To ensure the efficacy of vaccines against new variants, booster doses or optimization of original vaccines with updated $\mathrm{S}$ protein can also be considered after detailed quality assessment and safety trials.

SARS-CoV-2 is highly probable to mutate and evolve to enhance its infectivity and transmissibility, posing a severe risk of accumulation and dominance of immunologically relevant mutations across different lineages in the near future. Accumulation of single or multiple mutations at the RBD-ACE2 interface can lead to more deadly waves of COVID-19. A thorough inspection of hot-spot residues, genomic epidemiology, evolutionary history, and selective pressures can help to predict new mutations. Development of drug resistance to evade host immunity can also arise, and it is imperative to plan a solution for it beforehand. Sitedirected mutagenesis using high-throughput computational and molecular tools can help predict new mutations that can increase or decrease the affinity towards the ACE2 receptor $[48,102,103]$. These strategies can help in redesign available therapeutic and prophylactic interventions for avoiding cross-species transmission and for efficient management of re-emerging waves of COVID-19.

New variants have changed the game and the emergence of variants with improved transmissibility and infectivity have put the current control efforts and pandemic situation more severe than it was before. A more alarming situation that could arise in near future is the advent of better-adapted variants that would display additional properties to overcome the immunity conferred by vaccinations or prior infection. Prompt vaccine rollouts alone are no longer a guarantee of victory against these emerging variants and implementation of strong public health measures are urgently required. To ensure maximum suppression of virus and to flatten the curve, effective antiviral drugs, improved healthcare infrastructure, availability of hospital beds and oxygen supply, the establishment of more COVID-testing centers, isolation of infected patients, social distancing, and wearing masks are the potential measures that could abate SARS-CoV-2 spread.

Author Contributions Conceptualization: SC; AD; ST; PK. Writingoriginal draft preparation: SC, AD and ST. Writing-review and editing: SC, AD; ST; PK. ST and PK critically supervised and revised the manuscript. All authors read and approved the final manuscript. 
Funding The authors duly acknowledge the financial support from Science and Engineering Research Board, Department of Science \& Technology, Government of India under scheme Intensification of Research in High Priority Area (IRHPA) (Project no. IPA/2020/000054).

Data Availability Not applicable.

\section{Declarations}

Conflict of interest The authors declare no conflict of interest.

Ethical Approval Not applicable.

Consent to Participate Not applicable.

\section{References}

1. Home-Johns Hopkins Coronavirus Resource Center. https:// coronavirus.jhu.edu/. Accessed 2 June 2021

2. Korber B, Fischer WM, Gnanakaran S et al (2020) Tracking changes in SARS-CoV-2 spike: evidence that D614G increases infectivity of the COVID-19 virus. Cell 182:812-827.e19. https:// doi.org/10.1016/j.cell.2020.06.043

3. Zhang J, Cai Y, Xiao T et al (2021) Structural impact on SARSCoV-2 spike protein by D614G substitution. Science 372:525530. https://doi.org/10.1126/science.abf2303

4. Rani PR, Imran M, Lakshmi JV et al (2021) Symptomatic reinfection of SARS-CoV-2 with spike protein variant N440K associated with immune escape. J Med Virol 93:4163-4165. https:// doi.org/10.1002/jmv.26997

5. Deng X, Garcia-Knight MA, Khalid MM et al (2021) Transmission, infectivity, and neutralization of a spike L452R SARSCoV-2 variant. Cell. https://doi.org/10.1016/j.cell.2021.04.025

6. Motozono C, Toyoda M, Zahradnik J et al (2021) An emerging SARS-CoV-2 mutant evading cellular immunity and increasing viral infectivity. bioRxiv. https://doi.org/10.1101/2021.04.02. 438288

7. Harvey WT, Carabelli AM, Jackson B et al (2021) SARS-CoV-2 variants, spike mutations and immune escape. Nat Rev Microbiol 19:409-424. https://doi.org/10.1038/s41579-021-00573-0

8. Volz E, Hill V, McCrone JT et al (2021) Evaluating the effects of SARS-CoV-2 spike mutation D614G on transmissibility and pathogenicity. Cell 184:64-75.e11. https://doi.org/10.1016/j.cell. 2020.11.020

9. Ascoli CA (2021) Could mutations of SARS-CoV-2 suppress diagnostic detection? Nat Biotechnol 39:274-275. https://doi.org/ 10.1038/s41587-021-00845-3

10. Gordon DE, Jang GM, Bouhaddou M et al (2020) A SARSCoV-2 protein interaction map reveals targets for drug repurposing. Nature 583:459-468. https://doi.org/10.1038/ s41586-020-2286-9

11. Mudgal R, Nehul S, Tomar S (2020) Prospects for mucosal vaccine: shutting the door on SARS-CoV-2. Hum Vaccines Immunother 16:2921-2931. https://doi.org/10.1080/21645515.2020. 1805992

12. Choudhary S, Malik YS, Tomar S (2020) Identification of SARSCoV-2 cell entry inhibitors by drug repurposing using in silico structure-based virtual screening approach. Front Immunol 11:1664. https://doi.org/10.3389/fimmu.2020.01664

13. Bestle D, Heindl MR, Limburg $\mathrm{H}$ et al (2020) TMPRSS2 and furin are both essential for proteolytic activation of SARS-CoV-2 in human airway cells. Life Sci Alliance 3:e202000786. https:// doi.org/10.26508/1sa.202000786

14. Chi X, Yan R, Zhang J et al (2020) A neutralizing human antibody binds to the N-terminal domain of the Spike protein of SARS-CoV-2. Science 369:650-655. https://doi.org/10.1126/ science.abc6952

15. Yadav R, Chaudhary JK, Jain N et al (2021) Role of structural and non-structural proteins and therapeutic targets of SARSCoV-2 for COVID-19. Cells 10:821

16. SARS-CoV-2 variant classifications and definitions. https:// www.cdc.gov/coronavirus/2019-ncov/variants/variant-info.html. Accessed 2 June 2021

17. Cella E, Benedetti F, Fabris $S$ et al (2021) SARS-CoV-2 lineages and sub-lineages circulating worldwide: a dynamic overview. Chemotherapy 66:3-7. https://doi.org/10.1159/000515340

18. González-Candelas F, Shaw M-A, Phan T et al (2021) One year into the pandemic: short-term evolution of SARS-CoV-2 and emergence of new lineages. Infect Genet Evol 92:104869. https:// doi.org/10.1016/j.meegid.2021.104869

19. Rambaut A, Holmes EC, O'Toole Á et al (2020) A dynamic nomenclature proposal for SARS-CoV-2 lineages to assist genomic epidemiology. Nat Microbiol 5:1403-1407. https://doi. org/10.1038/s41564-020-0770-5

20. O'Toole Á, Pybus OG, Abram ME et al (2021) Pango lineage designation and assignment using SARS-CoV-2 spike gene nucleotide sequences. bioRxiv. https://doi.org/10.1101/2021. 08.10.455799

21. Statement of Nomenclature Rules-Pango Network. https:// www.pango.network/the-pango-nomenclature-system/statementof-nomenclature-rules/. Accessed 23 June 2021

22. Tracking SARS-CoV-2 variants. https://www.who.int/en/activ ities/tracking-SARS-CoV-2-variants/. Accessed 22 June 2021

23. Tregoning JS, Flight KE, Higham SL et al (2021) Progress of the COVID-19 vaccine effort: viruses, vaccines and variants versus efficacy, effectiveness and escape. Nat Rev Immunol 21:626-636. https://doi.org/10.1038/s41577-021-00592-1

24. Status of COVID-19 Vaccines within WHO EUL/PQ evaluation process. (2021). https://extranet.who.int/pqweb/sites/defau 1t/files/documents/Status_COVID_VAX_23Apri12021.pdf. Accessed 13 Dec 2021

25. Krammer F (2020) SARS-CoV-2 vaccines in development Nature 586:516-527. https://doi.org/10.1038/s41586-020-2798-3

26. Collier DA, De Marco A, Ferreira IATM et al (2021) Sensitivity of SARS-CoV-2 B.1.1.7 to mRNA vaccine-elicited antibodies. Nature 593:136-141. https://doi.org/10.1038/ s41586-021-03412-7

27. Coronavirus (COVID-19) update: FDA authorizes monoclonal antibodies for treatment of COVID-19 I FDA. https://www.fda. gov/news-events/press-announcements/coronavirus-covid-19update-fda-authorizes-monoclonal-antibodies-treatment-covid19. Accessed 20 June 2021

28. Plante JA, Liu Y, Liu J et al (2021) Spike mutation D614G alters SARS-CoV-2 fitness. Nature 592:116-121. https://doi.org/10. 1038/s41586-020-2895-3

29. Weissman D, Alameh M-G, de Silva T et al (2021) D614G spike mutation increases SARS CoV-2 susceptibility to neutralization. Cell Host Microbe 29:23-31.e4. https://doi.org/10.1016/j.chom. 2020.11.012

30. Yurkovetskiy L, Wang X, Pascal KE et al (2020) Structural and functional analysis of the D614G SARS-CoV-2 spike protein variant. Cell 183:739-751.e8. https://doi.org/10.1016/j.cell.2020. 09.032

31. Isabel S, Graña-Miraglia L, Gutierrez JM et al (2020) Evolutionary and structural analyses of SARS-CoV-2 D614G spike protein mutation now documented worldwide. Sci Rep 10:14031. https:// doi.org/10.1038/s41598-020-70827-z 
32. Jackson CB, Zhang L, Farzan M, Choe H (2021) Functional importance of the D614G mutation in the SARS-CoV-2 spike protein. Biochem Biophys Res Commun 538:108-115. https:// doi.org/10.1016/j.bbrc.2020.11.026

33. Dearlove B, Lewitus E, Bai H et al (2020) A SARS-CoV-2 vaccine candidate would likely match all currently circulating variants. Proc Natl Acad Sci USA 117:23652-23662. https://doi.org/ 10.1073/pnas.2008281117

34. McAuley AJ, Kuiper MJ, Durr PA et al (2020) Experimental and in silico evidence suggests vaccines are unlikely to be affected by D614G mutation in SARS-CoV-2 spike protein. Npj Vaccines 5:96. https://doi.org/10.1038/s41541-020-00246-8

35. Thomson EC, Rosen LE, Shepherd JG et al (2021) Circulating SARS-CoV-2 spike N439K variants maintain fitness while evading antibody-mediated immunity. Cell 184:1171-1187.e20. https://doi.org/10.1016/j.cell.2021.01.037

36. Tandel D, Gupta D, Sah V, Harinivas Harshan K (2021) N440K variant of SARS-CoV-2 has higher infectious fitness. bioRxiv. https://doi.org/10.1101/2021.04.30.441434

37. Singh J, Ehtesham NZ, Rahman SA, Hasnain SE (2021) Structure-function investigation of a new VUI-202012/01 SARSCoV-2 variant. bioRxiv. https://doi.org/10.1101/2021.01.01. 425028

38. Weisblum Y, Schmidt F, Zhang F et al (2020) Escape from neutralizing antibodies by SARS-CoV-2 spike protein variants. Elife. https://doi.org/10.7554/eLife.61312

39. Hoffmann M, Zhang L, Krüger N et al (2021) SARS-CoV-2 mutations acquired in mink reduce antibody-mediated neutralization. Cell Rep. https://doi.org/10.1016/j.celrep.2021.109017

40. van Dorp L, Tan CCS, Lam SD et al (2020) Recurrent mutations in SARS-CoV-2 genomes isolated from mink point to rapid hostadaptation. bioRxiv. https://doi.org/10.1101/2020.11.16.384743

41. Grabowski F, Preibisch G, Giziński S et al (2021) SARS-CoV-2 variant of concern 202012/01 has about twofold replicative advantage and acquires concerning mutations. Viruses 13:392

42. Bartolini B, Rueca M, Gruber CEM et al (2020) The newly introduced SARS-CoV-2 variant A222V is rapidly spreading in Lazio region, Italy. medRxiv. https://doi.org/10.1101/2020.11.28.20237016

43. Hodcroft EB, Zuber M, Nadeau S et al (2020) Emergence and spread of a SARS-CoV-2 variant through Europe in the summer of 2020. medRxiv. https://doi.org/10.1101/2020.10.25.20219063

44. Fournier P-E, Colson P, Levasseur A et al (2021) Emergence and outcomes of the SARS-CoV-2 'Marseille-4' variant. Int J Infect Dis 106:228-236. https://doi.org/10.1016/j.ijid.2021.03.068

45. Copin R, Baum A, Wloga E et al (2021) The monoclonal antibody combination REGEN-COV protects against SARS-CoV-2 mutational escape in preclinical and human studies. Cell. https:// doi.org/10.1016/j.cell.2021.06.002

46. Chakraborty S (2021) Evolutionary and structural analysis elucidates mutations on SARS-CoV2 spike protein with altered human ACE2 binding affinity. Biochem Biophys Res Commun 534:374-380. https://doi.org/10.1016/j.bbrc.2020.11.075

47. Koenig P-A, Das H, Liu H et al (2021) Structure-guided multivalent nanobodies block SARS-CoV-2 infection and suppress mutational escape. Science 371:eabe6230. https://doi.org/10. 1126/science.abe6230

48. Greaney AJ, Starr TN, Gilchuk P et al (2021) Complete mapping of mutations to the SARS-CoV-2 spike receptor-binding domain that escape antibody recognition. Cell Host Microbe 29:44-57. e9. https://doi.org/10.1016/j.chom.2020.11.007

49. Starr TN, Greaney AJ, Dingens AS, Bloom JD (2021) Complete map of SARS-CoV-2 RBD mutations that escape the monoclonal antibody LY-CoV555 and its cocktail with LY-CoV016. Cell Rep Med 2:100255. https://doi.org/10.1016/j.xcrm.2021.100255

50. Galloway SE, Paul P, MacCannell DR et al (2021) Emergence of SARS-CoV-2 B.1.1.7 Lineage-United States, december
29, 2020-january 12, 2021. MMWR Morb Mortal Wkly Rep 70:95-99. https://doi.org/10.15585/mmwr.mm7003e2

51. CoVariants. https://covariants.org/variants. Accessed 3 July 2021

52. Gupta RK (2021) Will SARS-CoV-2 variants of concern affect the promise of vaccines? Nat Rev Immunol 21:340-341. https://doi.org/10.1038/s41577-021-00556-5

53. McCallum M, De Marco A, Lempp FA et al (2021) N-terminal domain antigenic mapping reveals a site of vulnerability for SARS-CoV-2. Cell 184:2332-2347.e16. https://doi.org/10. 1016/j.cell.2021.03.028

54. Starr TN, Greaney AJ, Hilton SK et al (2020) Deep MUTATIONAL scanning of SARS-CoV-2 receptor binding domain reveals constraints on folding and ACE2 binding. Cell 182:1295-1310.e20. https://doi.org/10.1016/j.cell.2020.08.012

55. Graham MS, Sudre CH, May A et al (2021) The effect of SARS-CoV-2 variant B.1.1.7 on symptomatology, re-infection and transmissibility. medRxiv. https://doi.org/10.1101/2021. 01.28 .21250680

56. Davies NG, Jarvis CI, van Zandvoort K et al (2021) Increased mortality in community-tested cases of SARS-CoV-2 lineage B.1.1.7. Nature 593:270-274. https://doi.org/10.1038/ s41586-021-03426-1

57. Davies NG, Abbott S, Barnard RC et al (2021) Estimated transmissibility and impact of SARS-CoV-2 lineage B.1.1.7 in England. Science 372:eabg3055. https://doi.org/10.1126/science. $\operatorname{abg} 3055$

58. Wu K, Werner AP, Moliva JI et al (2021) mRNA-1273 vaccine induces neutralizing antibodies against spike mutants from global SARS-CoV-2 variants. bioRxiv. https://doi.org/10.1101/ 2021.01.25.427948

59. Supasa P, Zhou D, Dejnirattisai W et al (2021) Reduced neutralization of SARS-CoV-2 B.1.1.7 variant by convalescent and vaccine sera. Cell 184:2201-2211.e7. https://doi.org/10.1016/j. cell.2021.02.033

60. Pinto D, Park Y-J, Beltramello M et al (2020) Cross-neutralization of SARS-CoV-2 by a human monoclonal SARSCoV antibody. Nature 583:290-295. https://doi.org/10.1038/ s41586-020-2349-y

61. Ku Z, Xie X, Hinton PR et al (2021) Nasal delivery of an IgM offers broad protection from SARS-CoV-2 variants. Nature. https://doi.org/10.1038/s41586-021-03673-2

62. Tarke A, Sidney J, Methot N et al (2021) Negligible impact of SARS-CoV-2 variants on CD4+ and CD8+ T cell reactivity in COVID-19 exposed donors and vaccinees. bioRxiv. https:// doi.org/10.1101/2021.02.27.433180

63. McCallum M, Bassi J, De Marco A et al (2021) SARS-CoV-2 immune evasion by variant B.1.427/B.1.429. bioRxiv. https:// doi.org/10.1101/2021.03.31.437925

64. Copin R, Baum A, Wloga E et al (2021) In vitro and in vivo preclinical studies predict REGEN-COV protection against emergence of viral escape in humans. bioRxiv. https://doi.org/ $10.1101 / 2021.03 .10 .434834$

65. Baum A, Kyratsous CA (2021) SARS-CoV-2 spike therapeutic antibodies in the age of variants. J Exp Med. https://doi.org/10. 1084/jem.20210198

66. Westendorf K, Žentelis S, Foster D et al (2021) LY-CoV1404 potently neutralizes SARS-CoV-2 variants. bioRxiv. https:// doi.org/10.1101/2021.04.30.442182

67. Martinez DR, Schaefer A, Gobeil S et al (2021) A broadly neutralizing antibody protects against SARS-CoV, pre-emergent bat CoVs, and SARS-CoV-2 variants in mice. bioRxiv. https:// doi.org/10.1101/2021.04.27.441655

68. Cele S, Gazy I, Jackson L et al (2021) Escape of SARS-CoV-2 501Y.V2 from neutralization by convalescent plasma. Nature 593:142-146. https://doi.org/10.1038/s41586-021-03471-w 
69. Li Q, Nie J, Wu J et al (2021) SARS-CoV-2 501Y.V2 variants lack higher infectivity but do have immune escape. Cell 184:2362-2371.e9. https://doi.org/10.1016/j.cell.2021.02.042

70. Tegally H, Wilkinson E, Giovanetti M et al (2021) Detection of a SARS-CoV-2 variant of concern in South Africa. Nature 592:438-443. https://doi.org/10.1038/s41586-021-03402-9

71. Tang JW, Toovey OTR, Harvey KN, Hui DDS (2021) Introduction of the South African SARS-CoV-2 variant 501Y.V2 into the UK. J Infect 82:e8-e10. https://doi.org/10.1016/j.jinf.2021.01.007

72. Wibmer CK, Ayres F, Hermanus T et al (2021) SARS-CoV-2 501Y.V2 escapes neutralization by South African COVID-19 donor plasma. Nat Med 27:622-625. https://doi.org/10.1038/ s41591-021-01285-x

73. Zhou D, Dejnirattisai W, Supasa P et al (2021) Evidence of escape of SARS-CoV-2 variant B.1.351 from natural and vaccine-induced sera. Cell 184:2348-2361.e6. https://doi.org/10. 1016/j.cell.2021.02.037

74. Huang B, Dai L, Wang H et al (2021) Serum sample neutralisation of BBIBP-CorV and ZF2001 vaccines to SARS-CoV-2 501Y.V2. Lancet Microbe. https://doi.org/10.1016/S26665247(21)00082-3

75. Naveca F, da Costa C, Nascimento V et al (2021) Three SARSCoV-2 reinfection cases by the new variant of concern (VOC) P.1/501Y.V3. Res Sq. https://doi.org/10.21203/rs.3.rs-318392/v1

76. Li M, Lou F, Fan H (2021) SARS-CoV-2 variants: a new challenge to convalescent serum and mRNA vaccine neutralization efficiency. Signal Transduct Target Ther 6:151. https://doi.org/ 10.1038/s41392-021-00592-6

77. Faria NR, Mellan TA, Whittaker C et al (2021) Genomics and epidemiology of the P.1 SARS-CoV-2 lineage in Manaus, Brazil. Science 372:815-821. https://doi.org/10.1126/science. abh2644

78. de Souza WM, Amorim MR, Sesti-Costa R et al (2021) Levels of SARS-CoV-2 lineage P.1 neutralization by antibodies elicited after natural infection and vaccination. SSRN Electron J. https://doi.org/10.2139/ssrn.3793486

79. Hoffmann M, Arora P, Groß R et al (2021) SARS-CoV-2 variants B.1.351 and P.1 escape from neutralizing antibodies. Cell 184:2384-2393.e12. https://doi.org/10.1016/j.cell.2021.03.036

80. Vaidyanathan G (2021) Coronavirus variants are spreading in India - what scientists know so far. Nature 593:321-322. https://doi.org/10.1038/d41586-021-01274-7

81. Cherian S, Potdar V, Jadhav S et al (2021) Convergent evolution of SARS-CoV-2 spike mutations, L452R, E484Q and P681R, in the second wave of COVID-19 in Maharashtra, India. bioRxiv. https://doi.org/10.1101/2021.04.22.440932

82. Kannan SR, Spratt AN, Cohen AR et al (2021) Evolutionary analysis of the Delta and Delta Plus variants of the SARSCoV-2 viruses. J Autoimmun 124:102715. https://doi.org/10. 1016/j.jaut.2021.102715

83. Planas D, Veyer D, Baidaliuk A et al (2021) Reduced sensitivity of infectious SARS-CoV-2 variant B.1.617.2 to monoclonal antibodies and sera from convalescent and vaccinated individuals. bioRxiv. https://doi.org/10.1101/2021.05.26.445838

84. Saito A, Irie T, Suzuki R, et al (2021) SARS-CoV-2 spike P681R mutation, a hallmark of the Delta variant, enhances viral fusogenicity and pathogenicity. BioRxiv. https://doi.org/ 10.1101/2021.06.17.448820

85. Mlcochova P, Kemp S, Dhar MS et al (2021) SARS-CoV-2 B.1.617.2 Delta variant replication and immune evasion. Nature. https://doi.org/10.1038/s41586-021-03944-y

86. Behrens GM, Cossmann A, Stankov MV et al (2021) SARSCoV-2 Delta variant neutralisation after heterologous ChAdOx1S/BNT162b2 vaccination. Lancet (London, England) 398:10411042. https://doi.org/10.1016/S0140-6736(21)01891-2
87. Hammerschmidt SI, Bosnjak B, Bernhardt G et al (2021) Neutralization of the SARS-CoV-2 Delta variant after heterologous and homologous BNT162b2 or ChAdOx1 nCoV-19 vaccination. Cell Mol Immunol 18:2455-2456. https://doi.org/10. 1038/s41423-021-00755-Z

88. Sapkal GN, Yadav PD, Sahay RR et al (2021) Neutralization of Delta variant with sera of Covishield ${ }^{\mathrm{TM}}$ vaccinees and COVID19 recovered vaccinated individuals. J Travel Med. https://doi. org/10.1093/jtm/taab119

89. Hoffmann M, Hofmann-Winkler H, Krüger N et al (2021) SARS-CoV-2 variant B.1.617 is resistant to Bamlanivimab and evades antibodies induced by infection and vaccination. bioRxiv. https://doi.org/10.1101/2021.05.04.442663

90. Yadav PD, Sapkal GN, Abraham P et al (2021) Neutralization of variant under investigation B.10617 with sera of BBV152 vaccinees. bioRxiv. https://doi.org/10.1101/2021.04.23.441101

91. Lasek-Nesselquist E, Lapierre P, Schneider E et al (2021) The localized rise of a B.1.526 SARS-CoV-2 variant containing an E484K mutation in New York State. medRxiv. https://doi.org/ 10.1101/2021.02.26.21251868

92. Annavajhala MK, Mohri H, Wang P et al (2021) A novel and expanding SARS-CoV-2 variant, B.1.526, identified in New York. medRxiv. https://doi.org/10.1101/2021.02.23.21252259

93. Zahradník J, Marciano S, Shemesh M et al (2021) SARSCoV-2 RBD in vitro evolution follows contagious mutation spread, yet generates an able infection inhibitor. bioRxiv. https://doi.org/10.1101/2021.01.06.425392

94. Thompson CN, Hughes S, Ngai S et al (2021) Rapid emergence and epidemiologic characteristics of the SARS-CoV-2 B.1.526 variant-New York City, New York, january 1-april 5, 2021. MMWR Morb Mortal Wkly Rep 70:712-716. https://doi.org/ 10.15585/mmwr.mm7019e1

95. SARS-CoV-2 variants of concern and variants under investigation in England, technical briefing 7. https://assets.publi shing.service.gov.uk/government/uploads/system/uploads/attac hment_data/file/972247/Variants_of_Concern_VOC_Techn ical_Briefing_7_England.pdf. Accessed 3 June 2021

96. Zhou H, Dcosta BM, Samanovic MI et al (2021) B.1.526 SARS-CoV-2 variants identified in New York City are neutralized by vaccine-elicited and therapeutic monoclonal antibodies. bioRxiv. https://doi.org/10.1101/2021.03.24.436620

97. Kuzmina A, Khalaila Y, Voloshin O et al (2021) SARS-CoV-2 spike variants exhibit differential infectivity and neutralization resistance to convalescent or post-vaccination sera. Cell Host Microbe 29:522-528.e2. https://doi.org/10.1016/j.chom.2021. 03.008

98. The coronavirus is mutating-but what determines how quickly? https://www.nationalgeographic.com/science/article/ the-coronavirus-is-mutating-but-what-determines-how-quickly. Accessed 2 Oct 2021

99. Banerjee A, Mossman K, Grandvaux N (2021) Molecular determinants of SARS-CoV-2 variants. Trends Microbiol 29:871-873. https://doi.org/10.1016/j.tim.2021.07.002

100. Ozono S, Zhang Y, Ode H et al (2021) SARS-CoV-2 D614G spike mutation increases entry efficiency with enhanced ACE2binding affinity. Nat Commun 12:848. https://doi.org/10.1038/ s41467-021-21118-2

101. Burioni R, Topol EJ (2021) Assessing the human immune response to SARS-CoV-2 variants. Nat Med 27:571-572. https://doi.org/10.1038/s41591-021-01290-0

102. Padhi AK, Tripathi T (2020) Can SARS-CoV-2 accumulate mutations in the S-protein to increase pathogenicity? ACS Pharmacol Transl Sci 3:1023-1026. https://doi.org/10.1021/ acsptsci.0c00113

103. Greaney AJ, Starr TN, Barnes CO et al (2021) Mapping mutations to the SARS-CoV-2 RBD that escape binding by different 
classes of antibodies. Nat Commun 12:4196. https://doi.org/ 10.1038/s41467-021-24435-8

104. Focosi D, Maggi F (2021) Neutralising antibody escape of SARS-CoV-2 spike protein: risk assessment for antibody-based Covid-19 therapeutics and vaccines. Rev Med Virol. https:// doi.org/10.1002/rmv.2231
Publisher's Note Springer Nature remains neutral with regard to jurisdictional claims in published maps and institutional affiliations. 